\title{
Comparison of Clinical Performance and Subjective Outcomes Between Two Diffractive Trifocal Intraocular Lenses (IOLs) and One Monofocal IOL in Bilateral Cataract Surgery
}

\author{
Aurelio Imburgia ( $\sim$ aurelioimburgia@yahoo.it ) \\ State Hospital of the San Marino Republic: Ospedale di Stato della Repubblica di San Marino \\ https://orcid.org/0000-0003-4042-1910 \\ Francesco Gaudenzi \\ State Hospital of the San Marino Republic: Ospedale di Stato della Repubblica di San Marino \\ Kira Mularoni \\ State Hospital of the San Marino Republic: Ospedale di Stato della Repubblica di San Marino \\ Gloria Mussoni \\ State Hospital of the San Marino Republic: Ospedale di Stato della Repubblica di San Marino \\ Alessandro Mularoni \\ State Hospital of the San Marino Republic: Ospedale di Stato della Repubblica di San Marino
}

\section{Research Article}

Keywords: Trifocal IOL, Cataract surgery, PanOptix IOL, RayOne Trifocal IOL, Quality of vision

Posted Date: July 7th, 2021

DOI: https://doi.org/10.21203/rs.3.rs-662617/v1

License: (c) (i) This work is licensed under a Creative Commons Attribution 4.0 International License. Read Full License 


\section{Abstract}

Purpose: To compare clinical outcomes and subjective experience after bilateral implantation of two diffractive trifocal and one monofocal intraocular lenses (IOLs).

Methods: Fourty-eight patients were allocated to receive bilateral implantation of the RayOne Trifocal IOL (Rayner), the AcrySof IQ PanOptix IOL (Alcon), or the AcrySof IQ SN60WF IOL (Alcon). At 1-month, 3-month, and 12-month follow-up visits, the tested outcomes were monocular and binocular uncorrected and corrected distance, intermediate at $70 \mathrm{~cm}$, and near at $30 \mathrm{~cm}$ visual acuities, subjective refractive outcomes, defocus curves, contrast sensitivity and ocular aberrometry. Subjective patient satisfaction in terms of visual disturbance and spectacle independence was also evaluated.

Results: Each group comprised 32 eyes (16 patients). Refractive outcomes of RayOne and PanOptix IOLs were comparable. Both trifocal IOLs demonstrated superior visual acuity to the AcrySof monofocal IOL at near and intermediate ranges and along the defocus curves at all points other than at $0.0 \mathrm{D}$. The patient satisfaction results were comparable between the RayOne and PanOptix trifocal IOL groups.

Conclusion: Both trifocals performed similarly providing good visual outcomes at all distances, demonstrating superior visual acuity compared to the monofocal IOL. Patients implanted with these trifocal IOLs reported similar levels of quality of vision and satisfaction. The RayOne trifocal and PanOptix IOLs are a valuable alternative for patients wishing to seek spectacle independence and low visual disturbances when undergoing cataract surgery.

\section{Introduction}

Current available cataract surgery technologies not only improve vision but also help to enhance the patient's quality of life. Intraocular lenses (IOLs) play a key role in achieving the desired visual outcomes after surgery. Modern IOLs are available in a variety of materials, design, and optic features which can influence their visual performance [1].

Multifocal IOLs (MIOLs) are designed to distribute light to different foci dedicated to different distances and are designed to have either refractive or diffractive optics. In the past, conventional bifocal diffractive optics worked by splitting light using steps on the optic surface to create two principal focal points, thus providing good functional vision at distance and near [2]. Nevertheless, with bifocal IOLs the intermediate vision was compromised, thus making it difficult to perform some daily activities such as using a computer or seeing a car dashboard [1,3] without wearing spectacles [4]. In addition, bifocal IOLs were associated with some visual disturbances (e.g., glare and halos) and reduction of contrast sensitivity $[4,5]$.

The types of MIOLs available have undergone refinement in recent years with the attempt to offer excellent vision at far, intermediate and near distances while providing a low incidence of photic phenomena and high patient satisfaction. A new generation of multifocal lenses (trifocal IOLs) have been commercially available since 2010 [6]. These new types of lenses incorporate a third focal point to help improve intermediate vision while maintaining performance at distance and near [6-10]. With these newer trifocal IOLs, the freedom from wearing spectacles for seeing at intermediate distance helps to improve the patient's quality of life. However, the introduction of a third focal point might still have some drawbacks, such as dysphotopic phenomena such as halo and glare experienced under mesopic lighting conditions and reduced night vision. Moreover, splitting the light energy at three foci points (distance, intermediate, and near) may cause an increase in light loss, which may reduce the contrast sensitivity under certain lighting conditions. 
At present, different types of trifocal IOLs are available, with different haptic, material and optical designs, all attempting to offer optimal vision while ensuring a low incidence of photic phenomena and high patient satisfaction.

The AcrySof IQ PanOptix (Alcon Laboratories, Fort Worth, Tex., USA) which we will refer to as PanOptix hereafter, is a 1piece aspheric hydrophobic presbyopia-correcting IOL launched in 2015. The non-apodized PanOptix IOL uses the ENhanced LIGHT ENergy (ENLIGHTEN; Alcon Laboratories, Fort Worth, TX) optical technology that provides high (88\%) utilization of light energy, low dependence on pupil size in all lighting conditions, and a comfortable near-tointermediate range of vision than traditional bifocal IOLs [11]. The outcomes obtained with this lens in cataracts patients were demonstrated in non-comparative $[9,12-14]$ and comparative studies versus other new trifocal IOLs such as the Finevision IOL (PhysIOL; Liège, Belgium) [15,16].

The RayOne Trifocal (Rayner, Worthing, UK) which we will refer to as RayOne hereafter, is a newer addition to the MIOL family. It is a 1-piece aspheric hydrophilic IOL that was launched in 2017. It is designed with fewer diffractive rings on the optical surface than other currently used trifocal IOLs in order to reduce visual disturbances. RayOne is designed to reduce light loss to only $11 \%$ compared to $12-14 \%$ with other available trifocal lenses. The light distribution is $52 \%$ to distance, $22 \%$ to intermediate and $26 \%$ to near, thus allowing a smooth transition from near to intermediate and distance vision [10]. The RayOne has been objectively compared to the FineVision POD F and discussed in reviews along with other trifocal IOLs, such as the Sulcoflex Trifocal IOL [10,17].

The purpose of this study was to evaluate the postoperative visual and refractive outcomes, satisfaction and spectacle independence in patients whom underwent bilateral cataract surgery implanted with the RayOne or PanOptix. Since the two trifocal IOLs have different physical features and properties, we wanted to investigate whether the new RayOne provides comparable results to the PanOptix, for which excellent outcomes have already been published $[9,12-16]$. In addition, a monofocal IOL, the AcrySof IQ Monofocal SN60WF (Alcon Laboratories, Fort Worth, Tex., USA) which we will refer to as AcrySof monofocal hereafter, was also included into the study and used as a control for contrast sensitivity and ocular aberrometry.

\section{Methods}

Patients and study design

This prospective, comparative, non-randomized case-series study was performed at the San Marino State Hospital (Republic of San Marino). The study was conducted in accordance with the tenets of the Declaration of Helsinki, and the Institutional review board approval was obtained from the Hospitalmedico-legal committee prior to study commencement. Recruitment began in June 2018 and the enrolment was open for six months. Before entering into the study, all patients were fully informed on the surgical procedure and any vision concerns after IOL implantation were addressed, they were required to provide written consent for their surgical procedure and for allowing use of anonymized medical records for investigation purposes.

Patients presenting with bilateral cataract were included into the study and were scheduled for routine phacoemulsification cataract surgery, receiving one of the following IOLs: RayOne, PanOptix, or the AcrySof monofocal. Patients were included into the study if they were aged 18 years or older, if they had bilateral cataract limiting visual acuity, corneal astigmatism of $0.75 \mathrm{D}$ or less, and regular corneal tomography.

Exclusion criteria included previous ocular surgery (including refractive surgery), regular corneal astigmatism greater than $0.75 \mathrm{D}$, irregular astigmatism, large angle kappa and other optical or systemic conditions affecting visual acuity 
(such as macular disease, amblyopia, infection, ocular trauma, etc.), or anomalies of the lens capsule or zonules which could affect postoperative centration or tilt of the IOL (such as pseudoexfoliation syndrome).

Intraocular Lenses

The RayOne Trifocal (Rayner, Worthing, UK) is a one-piece hydrophilic aspheric lens that has an overall diameter of $12.5 \mathrm{~mm}$. The optic has a diameter of $6.0 \mathrm{~mm}$. The diffractive region covers the central $4.5 \mathrm{~mm}$ of the optic and thereafter the zone provides monocular distance vision. RayOne Trifocal (model RA0603F) has a patented diffractive profile with 16 rings on the optic surface for reduced potential visual disturbances and improved night vision. The haptic, which has an angulation of 0 degrees, consists of a closed loop with anti-vaulting haptic (AVH) technology that ensures rotational and centrational stability. The powers are available from 0.00 to $+30.00 \mathrm{D}$, in $0.50 \mathrm{D}$ increments. The addition powers are +3.5 D for near and +1.75 D for intermediate vision [10]. The IOL is preloaded in the RayOne injector system (Rayner, UK) across the entire power range and allows implantation through a $2.2 \mathrm{~mm}$ incision. This injector has a syringe-style design to aid a single-handed IOL delivery technique.

The AcrySof IQ PanOptix (Alcon Laboratories Inc., Fort Wort, TX, USA) is a panfocal IOL with quadrifocal technology. The IOL is a single piece made from hydrophobic acrylic with a $6.0 \mathrm{~mm}$ optic, 2 open-loop haptics, and an overall diameter of $13.0 \mathrm{~mm}$. The IOL incorporates an ultraviolet and blue light-filter. The optic diffractive structure is in the central $4.5 \mathrm{~mm}$ of the anterior surface with power additions of +2.17 D for intermediate and + 3.25 D for near [9,11] .

The AcrySof IQ monofocal IOL (Alcon Laboratories Inc) model SN60WF is a single-piece IOL with proprietary blue light filtering chromophores that filter light in a manner that approximates the crystalline lens in the $400-475 \mathrm{~nm}$ blue light wavelength range. The lens is made from a high refractive index soft acrylate/methacrylate copolymer and its configuration is anterior asymmetric biconvex. The posterior aspheric surface is designed with negative spherical aberration to compensate for the positive spherical aberration of an average cornea [18].

More technical specifications of the three IOLs are summarized in Table 1.

Surgical procedure

All surgeries were performed by the same experienced surgeon (AM) using topical anaesthesia. A standard technique of sutureless microincision phacoemulsification was performed for the implantation of the RayOne, PanOptix, and Acrysof monofocal IOLs; $2.4 \mathrm{~mm}$ corneal incision was placed in temporal side, the capsulorhexis diameter was $5.2 \mathrm{~mm}$ and the IOL was implanted in the capsular bag. The IOL centering and capsulorhexis size were performed with the assistance of an intraoperative digital system (Verion Image Guided System, Alcon Laboratories, Inc., Fort Worth, TX). No intraoperative complications occurred at any level during all surgeries.

Pre and Post-Operative Assessments

Preoperative assessments were performed at least 2 weeks before surgery. All patients underwent a full ophthalmologic examination for ocular morbidities, visual acuity, manifest refraction, and slit-lamp examination.

After surgery and at all follow-up visits, any visible decentration and tilt were assessed and documented. Postoperative complications were also assessed and documented. In addition to routine checks immediately after surgery, postoperative examinations were performed 1 month, 3 months, and 12 months after surgery. Postoperative follow-ups included assessments of the monocular and binocular uncorrected and corrected visual acuity at far (4 m), intermediate $(70 \mathrm{~cm})$, and near vision $(30 \mathrm{~cm})$. Distance visual acuity was assessed using the MOS 22 optotype (Dueffe Tecnovision, Pergine Valsugana, Italy) and was measured in LogMAR. Near and intermediate visual acuities 
were assessed using the MNREAD Acuity Chart (Precision Vision, LaSelle, IL). Subjective refraction was assessed only at the final follow-up visit and was performed using sphere, cylinder, and manifest residual spherical equivalent (MRSE) notations. The binocular defocus curves were evaluated under photopic conditions (85 candelas/m2) using defocusing lenses from -4.00 to $+2.00 \mathrm{D}$, in $0.50 \mathrm{D}$ steps of blur. Contrast sensitivity was assessed using the MOS 22 optotype at photopic $(85 \mathrm{~cd} / \mathrm{m} 2)$ and mesopic conditions $(6 \mathrm{~cd} / \mathrm{m} 2)$. Aberrometric examination was performed with Osiris aberrometer (Costruzione Strumenti Oftalmici, Florence, Italy) to evaluate low order (LOA) and high order (HOA) aberrations at full pupil diameter. Patient satisfaction and spectacle independence were determined using the selfadministered NEI-RQL-42 (National Eye Institute Refractive Error Quality of Life Instrument-42) questionnaire [19]. All examinations were performed by the same experienced examiner (Al) using the same investigative protocol.

Statistical analysis

The calculation of the required sample size was based on the monocular UDVA. Based on previous data analyses for a similar study [20], a difference of 0.1 logMAR units was assumed to be clinically significant and considered a standard deviation of 0.05 logMAR. Based on this assumption, it was calculated that for an alpha value of 0.05 and power of $0.80,30$ eyes were required in each group.

Statistical analysis was carried out with Excel Version 14.0.0 for Mac (Microsoft Corporation, Redmond, WA). Data from the three study groups were first compared together using a repeated-measures ANOVA. If significant differences were found, the groups were compared two at a time using the Student t test for independent samples for parametric data and the Mann-Whitney test for non-parametric data. A Welch test was used to compare two groups at a time in some items in the patient questionnaire. Categorical data was evaluated using the Fisher's Exact test for small samples. Differences were considered to be statistically significant if $P<0.05$.

\section{Results}

A total of 48 patients (96 eyes) with bilateral IOL implantation were included into the study. Each IOL group comprised 32 eyes of 16 patients. Patients' mean age was $69.7+7.8$ years (range: $52-83$ years, median: 71 years).

All patients had uneventful cataract surgery in both eyes and completed the 12-month follow-up. The intraocular lenses were well centered in all eyes and remained stable over time. No further surgical intervention was required after surgery.

\section{Refractive accuracy}

Compared to the preoperative values, significant improvements in the residual manifest sphere values over time were observed for each of the three IOLs (Time effect $F(1,47)=15.21, P<0.001$ ), with a mean manifest sphere value at the 12-month follow-up visit of $-0.03 \pm 0.13 \mathrm{D},-0.08 \pm 0.18 \mathrm{D}$, and-0.09 $\pm 0.20 \mathrm{D}$, for the RayOne, PanOptix, and the AcrySof monofocal IOLs, respectively. These values did not significantly vary among the three groups (Interaction effect, $F(2.45)=0.35, P=0.705)$, nor did they significantly vary at each follow-up visit (Group effect, $F(2,47)=1.08, P=0.595)$.

The cylinder did not statistically differ among the three IOL groups over time (Interaction effect, $F(2,45)=0.07, P=$ 0.9358 ), nor at each time visit (Group effect, $F(2,47)=0.37, P=0.6919)$. Overall, the cylinder values remained stable over time for each group (Time effect $F(1,47)=1.73, P=0.1949$ ), with a mean cylinder value at 12-month follow-up of $-0.11 \pm 0.13 \mathrm{D},-0.17 \pm 0.22 \mathrm{D}$, and-0.05 $\pm 0.41 \mathrm{D}$, for the RayOne, PanOptix, and the AcrySof monofocal IOLs, respectively. Figure $1, A$, shows the distribution of refractive cylinder; all eyes in the RayOne and PanOptix IOL groups were within $\pm 0.50 \mathrm{D}$ of the attempted correction. Of the AcrySof monofocal group, $75 \%$ of eyes were within $\pm 0.50 \mathrm{D}$ and $100 \%$ of eyes were within $\pm 1.00 \mathrm{D}$ of attempted correction. 
Compared to the preoperative values, a significant improvement in the postoperative residual manifest spherical equivalent over time was observed for each of the three IOLs (Time effect $F(1,47)=13.6, P<0.001$ ), with a MRSE measured at the final follow-up of $-0.08 \pm 0.15 D,-0.14 \pm 0.18 D$, and $-0.11 \pm 0.24 D$, for the RayOne, PanOptix, and the AcrySof monofocal IOL, respectively. These values did not significantly vary among the three groups (Interaction effect, $F(2,45)=0.27, P=0.7668$ ), nor did they significantly vary at each time visit (Group effect, $F(2,47)=0.33, P=0.7197$ ). Figure 1, B, shows the distribution of the MRSE in the three IOL groups. With all tested IOLs, all eyes were within \pm 0.50 $\mathrm{D}$ of the attempted correction and, therefore, also within $\pm 1 \mathrm{D}$ of intended correction.

Visual outcomes

All postoperative monocular uncorrected and corrected visual outcomes calculated at 1, 3, and 12 months after surgery are shown in Table 2, and all postoperative binocular uncorrected and corrected visual outcomes are shown in Table 3. A statistically significant difference was found in monocular and binocular uncorrected distance visual acuity (UDVA) among the three IOL groups at each follow-up visit (Group effect, $F(2,141)=4.05, P=0.024$; Group effect, $F(2,69)=$ $7.58, \mathrm{P}=0.003$ for monocular and binocular UDVA, respectively), with the RayOne IOL leading to better improvement in distance visual acuity compared to the other two IOLs $(P<0.01$, Tables 2 and 3$)$. Monocular and binocular distancecorrected visual acuity (DCVA) did not significantly differ between any of the postoperative measurements within each IOL group, nor was the degree of improvement significantly different between the treatment groups.

Figure 2, A, shows the cumulative distribution of monocular UDVA and DCVA for the three IOLs. The UDVA was 20/20 or better (logMAR equivalent 0.0 or better) in $63 \%$ of eyes in the AcrySof monofocal group, in $75 \%$ of eyes in the PanOptix group, and in $100 \%$ of eyes in the RayOne group. All eyes treated with each of the tested IOLs achieved a DCVA of $20 / 25$ or better (logMAR equivalent 0.1 or better).

Improvements in monocular and binocular uncorrected intermediate visual acuity (UIVA) significantly varied among the three IOL groups at each follow-up visit (Interaction effect, $F(6,135)=105.51, P<0.001$ ); interaction effect, $F(6,63)=$ $72.15, \mathrm{P}<0.001$ for monocular and binocular values, respectively), with the AcrySof monofocal group leading to worse UIVA compared to the other two IOL groups ( $P<0.001$, Tables 2 and 3 ). Monocular and binocular distance-corrected intermediate visual acuity (DCIVA) did not significantly change between any of the postoperative measurements within each group of IOLs, and the degree of improvement remained comparable between the treatment groups. The cumulative distribution of post-operative monocular UIVA and DCIVA is shown in Fig. 2, B. The UIVA was 20/25 or better (logMAR equivalent 0.1 or better) in 100\% of eyes in the RayOne group, in $94 \%$ of eyes in the PanOptix group; none of eyes in the AcrySof monofocal group achieved this acuity target. $100 \%$ of eyes in the RayOne and AcrySof monofocal groups and $94 \%$ of eyes in the PanOptix group achieved a DCIVA of $20 / 25$ or better.

A statistically significant difference was found in monocular and binocular uncorrected near visual acuity (UNVA) among the three IOL groups at each follow-up visit (Interaction effect, $F(6,135)=81.42, P<0.001$ ), with the AcrySof monofocal group leading to worse UNVA compared to the other two IOL groups $(P<0.001$, Tables 2 and 3$)$. Monocular and binocular distance-corrected near visual acuity (DCNVA) did not significantly differ between any of the postoperative measurements within each group of IOLs, nor was the degree of improvement significantly different between the treatment groups. Figure 2, C shows the cumulative distribution of monocular UNVA and DCNVA for the three IOL groups. The UNVA was $20 / 25$ or better (logMAR equivalent 0.1 or better) in $75 \%$ of eyes in the RayOne group, 
in $56 \%$ of eyes in the PanOptix group; none of eyes in the AcrySof monofocal group achieved this acuity target. All eyes in the RayOne and PanOptix groups achieved a DCNVA of 20/20 or better (logMAR equivalent 0.0 or better).

Defocus Curve

Defocus curves for the three treatment groups at 1 month, 3 months, and 12 months postoperative are depicted in Fig. 3. At each evaluation, peak visual acuity occurred in all three groups at $0.0 \mathrm{D}$, at which point there were no differences in visual acuity among the three treatment groups. With a couple of exceptions, both the RayOne and the PanOptix groups had significantly better visual acuity than the AcrySof monofocal group at every other defocus interval at every postoperative examination. The exceptions were: at 1 month postoperative, the RayOne and AcrySof monofocal groups were not significantly different at-0.5 D ( $P=0.097)$; and at 12 months postoperative, the RayOne and AcrySof monofocal groups were not significantly different at-0.5 D (P=0.089) and the PanOptix and AcrySof monofocal groups were not significantly different at +1.0 D ( $P=0.061)$. There were no significant differences between the RayOne and the PanOptix groups at any defocus interval.

\section{Contrast sensitivity}

Photopic and mesopic contrast sensitivity graphs (measured in log contrast threshold) for the three treatment groups at 1 month, 3 months, and 12 months after surgery are depicted in Fig. 4. Under both photopic and mesopic conditions, all three treatment groups peaked in contrast sensitivity at 3 cycles per degree of visual angle at all three postoperative timepoints. Likewise, under both photopic and mesopic condition and in all three postoperative evaluations, contrast sensitivity was significantly higher for the AcrySof monofocal group than either the RayOne or the PanOptix groups at every level in the range tested $(P<0.05$ for the 3-month evaluation under photopic conditions, and $P<0.001$ for all the other tests). There were no significant differences between the RayOne and the PanOptix groups at any spatial frequencies.

\section{Aberrometric outcomes}

Aberrometric examination was performed after surgery with the CSO aberrometer (OSIRIS) to evaluate Low order (LOA) and High Order ( $\mathrm{HOA})$ aberrations. Ocular, corneal and internal aberrations were assessed at 12 months after surgery in the three groups at full pupillary diameter. Full results are described in Table 4. Aberrometric data points were quantified in root mean square (RMS) values in micrometers $(\mu \mathrm{m})$, and mean values for both LOA and HOA aberrations compared between the RayOne and PanOptix groups, with the monofocal group used as a control group (Fig. 5). The mean pupillary diameter was not significantly different between all three groups $(p=0.374)$.

In the RayOne group, mean full pupillary diameter was $3.486 \pm 0.499$ millimeters. Overall total ocular aberrometry was $0.538 \pm 0.254 \mu \mathrm{m}$ with LOA $0.462 \pm 0.239 \mu \mathrm{m}$ and HOA $0.141 \pm 0.043 \mu \mathrm{m}$. The total corneal aberrometry was $0.226 \pm$ 0.111 with LOA $0.162 \pm 0.112 \mu \mathrm{m}$ and $\mathrm{HOA} 0.145 \pm 0.057 \mu \mathrm{m}$. The total internal aberrometry was $0.490 \pm 0.270$ with LOA $0.438 \pm 0.272 \mu \mathrm{m}$ and HOA $0.145 \pm 0.049 \mu \mathrm{m}$. Internal primary coma, primary trefoil and spherical aberration were $0.058 \pm 0.033 \mu \mathrm{m}, 0.071 \pm 0.038 \mu \mathrm{m}$ and $-0.004 \pm 0.049 \mu \mathrm{m}$ respectively.

In the PanOptix group, mean full pupillary diameter was $3.739 \pm 0.598$ millimeters. Overall total ocular aberrometry was $0.543 \pm 0.184 \mu \mathrm{m}$ with LOA $0.491 \pm 0.175 \mu \mathrm{m}$ and HOA $0.187 \pm 0.103 \mu \mathrm{m}$. The total corneal aberrometry was $0.246 \pm$ 
0.061 with LOA $0.188 \pm 0.059 \mu \mathrm{m}$ and $\mathrm{HOA} 0.146 \pm 0.058 \mu \mathrm{m}$. The total internal aberrometry was $0.539 \pm 0.242$ with LOA $0.471 \pm 0.183 \mu \mathrm{m}$ and HOA $0.176 \pm 0.076 \mu \mathrm{m}$. Internal primary coma, primary trefoil and spherical aberration were $0.071 \pm 0.059 \mu \mathrm{m}, 0.094 \pm 0.061 \mu \mathrm{m}$ and $0.013 \pm 0.032 \mu \mathrm{m}$ respectively.

In the AcrySof monofocal group, mean full pupillary diameter was $3.808 \pm 0.878$ millimeters. Overall total ocular aberrometry was $0.453 \pm 0.198 \mu \mathrm{m}$ with LOA $0.408 \pm 0.181 \mu \mathrm{m}$ and HOA $0.157 \pm 0.068 \mu \mathrm{m}$. The total corneal aberrometry was $0.243 \pm 0.066$ with LOA $0.181 \pm 0.098 \mu \mathrm{m}$ and HOA $0.154 \pm 0.062 \mu \mathrm{m}$. The total internal aberrometry was $0.426 \pm 0.205$ with LOA $0.348 \pm 0.170 \mu \mathrm{m}$ and HOA $0.147 \pm 0.060 \mu \mathrm{m}$. Internal primary coma, primary trefoil and spherical aberration were $0.085 \pm 0.049 \mu \mathrm{m}, 0.128 \pm 0.107 \mu \mathrm{m}$ and $0.014 \pm 0.036 \mu \mathrm{m}$ respectively.

The aberrometric values were similar in the three groups. The total ocular and internal aberrations showed lower values in the Acrysof Monofocal group compared to the PanOptix and RayOne groups, as well as the total ocular and internal LOA values. No statistically significant differences were identified between the three groups regarding total ocular and internal HOA values $(p>0.05)$. The total corneal aberrometry values were found to be lower in RayOne group (RayOne $0.226 \pm 0.111 \mu \mathrm{m}$, PanOptix $0.246 \pm 0.061 \mu \mathrm{m}$, Acrysof Monofocal $0.243 \pm 0.066 \mu \mathrm{m}$ ), but no statistically significant differences were found between the three groups.

Patient satisfaction

At the 12-month follow up, all patients implanted with either the RayOne or the PanOptix IOLs rated all items on the NEI RQL-42 Questionnaire highly (Fig. 6). All of these patients gave a score of 100 (corresponding to complete satisfaction) in the following categories: clarity of vision; diurnal fluctuations; activity limitations; worry about eyesight; appearance of their eyes; dependence on corrective lenses; problems with suboptimal correction; how well their expectations were met; and overall satisfaction with their correction. Patients in the RayOne group gave a mean score of 100 for near vision satisfaction, and those in the PanOptix group gave a mean score of 96.88 (range: 93.75-100); the mean score given for distance vision satisfaction in the RayOne group was 95.62 (range: 88.33-100), and was 92.08 (range: 78.33-100) in the PanOptix group. When scoring on dysphotopic phenomena, patients in the RayOne and PanOptix groups scored 92.23 (range: 70.83-100) and 84.38 (range: 37.5-100) for glare respectively. Additionally they gave a score of 100 and 91.52 (range: 71.42-100) for other optical symptoms, respectively. There were no significant differences in the responses to any of the questions between the RayOne and PanOptix groups.

\section{Discussion}

The goal of this study was to analyse and compare the clinical performance and subjective outcomes after the bilateral implantation of the RayOne Trifocal or the AcrySof IQ PanOptix intraocular lenses. In addition, the AcrySof IQ Monofocal SN60WF was also included into the study, in particular for the comparison of the performance in terms of contrast sensitivity and ocular aberrometry.

Recently, the RayOne Trifocal IOL has been objectively compared to the AcrySof IQ PanOptix trifocal IOLs [20]. However this study compared the RayOne Trifocal to the AcrySof IQ PanOptix with a 12 months follow-up adding new information such as the influence of these trifocal IOLs on ocular and internal aberrations.

The findings from this study indicated that RayOne Trifocal IOL continued to demonstrate good refractive outcomes following cataract surgery. Interestingly, the percentage of eyes treated with RayOne with a MRSE within + 0.13 D of the attempted correction was slightly higher compared to the PanOptix IOL (75\% vs. 56\%, respectively), which might suggest a higher predictability for RayOne; however, the postoperative MRSE was very close to emmetropia (within + $0.5 \mathrm{D}$ of the attempted correction) for all eyes in both IOL groups, which indicates a good performance for both IOLs. 
Ribeiro et al reported a MRSE within $\pm 0.50 \mathrm{D}$ in $73 \%, 97 \%$, and $77 \%$ of eyes treated with the POD F, RayOne, and PanOptix IOLs respectively [20]. In a previous comparative study on the RayOne and FineVision POD F, the MRSE was within $+0.5 \mathrm{D}$ of the attempted correction for all eyes treated with the RayOne at 3 months after surgery [10]. Our data agree with these results. The lack of significant differences in cylinder between any of the treatment groups nor across time was unsurprising, as no patients with more than $0.75 \mathrm{D}$ of astigmatism were included into the study.

The visual acuity results in this study demonstrated the RayOne and the PanOptix IOLs did not differ significantly in terms of visual acuity. Both treatment groups were superior to the monofocal control group in uncorrected monocular and binocular near and intermediate visual acuity. Interestingly, the visual acuity outcomes with the RayOne IOL calculated at 3 months after cataract surgery in this study were quite in line with the findings from the previous studies on RayOne. In our study the monocular UNVA was $0.01 \pm 0.05 \log M A R$, and was $0.04 \pm 0.13$ logMAR in study published by Ribeiro et al [20]; the monocular DCIVA and DCNVA in our study were $0.08 \pm 0.04 \log M A R$ and $0.00 \pm 0.00 \log M A R$, respectively, and were $0.04 \pm 0.13 \log M A R$ and $0.02 \pm 0.12 \log M A R$, respectively, in Riberio report [20]. Similar findings were reported by Ferreira et al [10] (0.03 $\pm 0.11 \log M A R, 0.05 \pm 0.13 \log M A R$, and $0.02 \pm 0.12 \log M A R$ for monocular UNVA, DCIVA, and DCNVA, respectively).

This study demonstrated that the two trifocal IOLs were superior to the monofocal lens not only in terms of visual acuity, but also along the defocus curves at all tested timepoints other than at $4 \mathrm{~m}$ ( $0.00 \mathrm{D}$ of defocus), where the best visual acuity was achieved with all IOLs, as expected.

For both the RayOne and PanOptix IOL, the visual acuity values achieved between-1.00 D and-2.50 D of defocus, corresponding to a distance between $80 \mathrm{~cm}$ and $40 \mathrm{~cm}$, respectively, were within the range of 0.00 to $0.01 \operatorname{logMAR}$, thus confirming that the performances of RayOne and PanOptix IOL in near, intermediate, and far vision were excellent and comparable between the two groups. Interestingly, the visual outcomes obtained with the RayOne IOL are comparable with those obtained in other studies performed on patients implanted with the PanOptix IOL [13-15, 20, 21].

Compared to the AcrySof monofocal IOL, both trifocal IOLs yielded lower contrast sensitivity at all angular frequencies tested. These results are not surprising, as it has been widely reported the incoming light distribution between two or more foci reduces contrast sensitivity [16]. Although a trend of a slightly better contrast sensitivity in photopic condition was observed in the RayOne group compared to PanOptix group, differences between groups did not show statistical significance for any spatial frequencies.

Aberrometry measurements did not on the whole differ between the three groups. The AcrySof monofocal had lower RMS values $(\mu \mathrm{m})$ for overall total ocular and internal aberrations compared to the other groups, likely related to the monofocal IOL design. The RayOne group showed lower values for overall total ocular aberrations and for internal HOA compared to the PanOptix group, whilst this was not statistically significant. The corneal aberrations were similar in the three groups, and were not related to the multifocal IOL design, as corneal aberrations are known to exist in normal corneas as a result of individual anatomy or refractive error [22]. Internal aberrations are considered mainly to be related to the IOL, and are known to a cause of visual disturbances due to dispersion of light inside the eye [21]. The overall low values for all internal aberrations in this study in all three groups indicates minimum light dispersion in the eye (Fig. 7). The RMS values for the HOAs of primary spherical aberration and coma, considered generally the most visual disabling aberrations, were very low in all three groups [23]. The RayOne group saw the lowest coma, trefoil and primary spherical aberration values, but there were no significant differences between the groups. RMS values in the context of the mean full pupillary diameter are favorable. The RayOne group had the smallest mean pupil diameter of the three groups (not significantly different to the two other groups). The optic size and the amount of diffractive steps for both diffractive IOLs are similiar (RayOne IOL 16 steps, 4.5 millimeter optic; PanOptix 15 steps, 4.5 millimeter optic) 
and these data may indicate that both IOLs are effective with pupil dependency. Compared to the control group (AcrySof monofocal), RayOne and PanOptix IOLs showed similar values of total and internal LOA and HOA, demonstrating a good quality of vision in these trifocal IOLs.

In terms of image quality, photic phenomena, especially glare and halos are known effects of MIOLs that may affect a patient's quality of life. To compare the incidence of visual disturbances between the two IOLs, we used the NEIRQL-42 questionnaire [19]. All patients implanted with RayOne lenses reported complete satisfaction with their visual outcomes, ocular health, and appearance one year after undergoing the surgery. Notably, all patients who received the RayOne IOL reported a $70 \%$ or higher satisfaction with regards to glare problems $(93.23 \pm 10.67 \%$ overall), contrasting with those who received the PanOptix IOL, where one individual reported a satisfaction of only $37.5 \%(84.38 \pm 25.66 \%$ for the group) with regards to glare. Similarly, all patients who received RayOne reported $100 \%$ satisfaction in other ocular symptoms and near vision, while some few individuals who received PanOptix reported less than complete satisfaction in these categories. Although these differences were not statistically significant, the statistical power was

likely impacted by the small group size ( $n=32$ eyes for each treatment). Future studies with larger cohorts may find the RayOne IOL to indeed yield higher patient satisfaction.

Finally, no posterior capsular opacification (PCO) was reported in any patients at the end of follow-up and the IOLs were centered and remained stable over time in all eyes (Fig. 8).

In conclusion, when comparing the performance of the RayOne Trifocal to the PanOptix Trifocal IOL, (which has been commercially available since 2015 and FDA approved in 2019), RayOne has been highly regarded among ophthalmologists, the results demonstrate that the RayOne Trifocal lens can provide as excellent visual acuity as the PanOptix IQ trifocal and high patient satisfaction without causing visual distortions, residual refractive error, optical discomfort, or other adverse effects.

Thus, this new trifocal IOL might represent a good alternative for patients undergoing cataract surgery who want to achieve a good range of vision and a low rate of visual disturbances.

\section{Declarations}

Fundings: No funding or grant support

Conflicts of interest/Competing interests: The authors have no conflicts of interest or competing interests

Availability of data and material: The authors confirm the validity of data and material

Code availability: Not applicable

Authors' contributions: All authors contributed to the composition of the manuscript

Acknowledgements: none

\section{References}


1. de Vries NE, Nuijts RMMA (2013) Multifocal intraocular lenses in cataract surgery: literature review of benefits and side effects. J Cataract Refract Surg 39:268-78.https://doi.org/1016/j.jcrs.2012.12.002

2. Lane SS, Morris M, Nordan L, Packer M, Tarantino N, Wallace RB 3rd (2006) Multifocal intraocular lenses. Ophthalmol Clin North Am 19:89-105.https://doi.org/10.1016/j.ohc.2005.09.002

3. Alfonso JF, Fernández-Vega L, Puchades C, Montés-Micó R (2010) Intermediate visual function with different multifocal intraocular lens models. J Cataract Refract Surg36:733-9.https://doi.org/10.1016/j.jcrs.2009.11.018

4. de Vries NE, Webers CAB, Touwslager WRH, Bauer NJC, de Brabander J, Berendschot TT, Nuijts RMMA (2011) Dissatisfaction after implantation of multifocal intraocular lenses. J Cataract Refract Surg37:859-65. https://doi.org/10.1016/j.jcrs.2010.11.032

5. Cochener B, Lafuma A, Khoshnood B, Courouve L, Berdeaux G (2011) Comparison of outcomes with multifocal intraocular lenses: a meta-analysis. Clin Ophthalmol;5:45-56.https://doi.org/10.2147/OPTH.S14325

6. Cochener B, Boutillier G, Lamard M, Auberger-Zagnoli C (2018) A comparative evaluation of a new generation of diffractive trifocal and extended depth of focus intraocular lenses. J Refract Surg34:507-

514.https://doi.org/10.3928/1081597X-20180530-02

7. Gatinel D, Houbrechts Y (2013) Comparison of bifocal and trifocal diffractive and refractive intraocular lenses using an optical bench. J Cataract Refract Surg39:1093-9.https://doi.org/10.1016/j.jcrs.2013.01.048

8. Carballo-Alvarez J, Vazquez-Molini JM, Sanz-Fernandez JC, Garcia-Bella J, Polo V, García-Feijoo J, Martinez-de-laCasa JM (2015) Visual outcomes after bilateral trifocal diffractive intraocular lens implantation. BMC Ophthalmol15:26.https://doi.org/10.1186/s12886-015-0012-4

9. Alio JL, Plaza-Puche AB, Alio Del Barrio JL, Amat-Peral P, Ortuño V, Yébana P, Al-Shymali O, Vega-Estrada A (2018) Clinical outcomes with a diffractive trifocal intraocular lens. Eur J Ophthalmol28:419-

424.https://doi.org/10.1177/1120672118762231

10. Ferreira TB, Ribeiro FJ (2019) Prospective Comparison of Clinical Performance and Subjective Outcomes Between Two Diffractive Trifocal Intraocular Lenses in Bilateral Cataract Surgery. J Refract Surg35:418-

425.https://doi.org/10.3928/1081597X-20190528-02

11. Sudhir RR, Dey A, Bhattacharrya S, Bahulayan A (2019) AcriSof IQ PanOptix intraocular lens versus extended depth of focus and trifocal intraocular lens: a clinical overview. Asia Pac J Ophthalmol (Phila)8:335349.https://doi.org/10.1097/AP0.0000000000000253

12. Kohnen T, Herzog M, Hemkeppler E, Schönbrunn S, De Lorenzo N, Petermann K, Böhm M (2017) Visual performance of a quadrifocal (trifocal) intraocular lens following removal of the crystalline lens. Am J Ophthalmol184:52-62.https://doi.org/10.1016/j.ajo.2017.09.016

13. Lawless M, Hodge C, Reich J, Levitz L, Bhatt UK, McAlinden C, Roberts K, Roberts TV (2017) Visual and refractive outcomes following implantation of a new trifocal intraocular lens. Eye Vis (Lond)4:10.

https://doi.org/10.1186/s40662-017-0076-8

14. Garcia-Perez JL, Gros-Otero J, Sancez-Ramos C, Blázquez V, Contreras I (2017) Short term visual outcomes of a new trifocal intraocular lens. BMC Ophthalmol17:72.https://doi.org/10.1186/s12886-017-0462-y

15. Gundersen KG, Potvin R (2017) Trifocal intraocular lenses: a comparison of the visual performance and quality of vision provided by two different lens designs. Clin Ophthalmol11:1081-

1087.https://doi.org/10.2147/OPTH.S136164

16. Martínez de Carneros-Llorente A,Martínez de Carneros A, Martínez de Carneros-Llorente P, Jiménez-Alfaro I (2019) Comparison of visual quality and subjective outcomes among 3 trifocal intraocular lenses and 1 bifocal intraocular lens. J Cataract Refract Surg45:587-594.https://doi.org/10.1016/j.jcrs.2018.12.005

Page $11 / 22$ 
17. McNeil R (2019) Newer generation IOL platforms designed for high-quality visual performance after cataract surgery. Eye News. Available in: https://www.eyenews.uk.com/features/ophthalmology/post/newer-generation-iolplatforms-designed-for-high-quality-visual-performance-after-cataract-surgery.

18. Lin IC, Wang IJ, Lei MS, Lin LLK, Hu FR (2008) Improvements in vision-related quality of life with AcrySof IQ SN60WF aspherical intraocular lenses. J Cataract Refract Surg34:1312-

7.https://doi.org/10.1016/j.jcrs.2008.04.028

19. McAlinden C, Skiadaresi E, Moore J, Pesudovs K (2011) Subscale Assessment of the NEI-RQL-42 Questionnaire with Rasch Analysis. Invest Ophthalmol Vis Sci52:5685-94.https://doi.org/10.1167/iovs.10-67951

20. Ribeiro F, Ferreira TB (2020) Comparison of clinical outcomes of 3 trifocal IOLs. J Cataract Refract Surg46:12471252.https://doi.org/10.1097/j.jcrs.0000000000000212

21. Escandón-García S, Ribeiro FJ, McAlinden C, Queirós A, González-Méijome JM (2018) Through-Focus Vision Performance and Light Disturbances of $3 \mathrm{New}$ Intraocular Lenses for Presbyopia Correction. J Ophthalmol2018:6165493. https://doi.org/10.1155/2018/6165493

22. Anbar M, Mostafa EM, Elhawary AM, Awny I, Farouk MM, Mounir A (2019) Evaluation of Corneal Higher-Order Aberrations by Scheimpflug-Placido Topography in Patients with Different Refractive Errors: A Retrospective Observational Study. J Ophthalmol2019:5640356.https://doi.org/10.1155/2019/5640356

23. Rocha KM, Vabre L, Harms F, Chateau N, Krueger RR (2007) Effects of Zernike wavefront aberrations on visual acuity measured using electromagnetic adaptive optics technology. J Refract Surg23:953-9

\section{Tables}


Table 1

Comparison of technical specifications of the three tested Intraocular lenses.

\begin{tabular}{|c|c|c|c|}
\hline Parameter & RayOne Trifocal & AcrySof IQ PanOptix & AcrySof IQ SN60WF \\
\hline Material & $\begin{array}{l}\text { Single piece Rayacrilß hydrophilic } \\
\text { acrylic }\end{array}$ & $\begin{array}{l}\text { Acrylate, } \\
\text { Methacrylate } \\
\text { Copolymer }\end{array}$ & $\begin{array}{l}\text { UV and blue filtering } \\
\text { Acrylate, Methacrylate } \\
\text { Copolymer }\end{array}$ \\
\hline Optical design & Diffractive & $\begin{array}{l}\text { Diffractive-refractive } \\
\text { hybrid }\end{array}$ & Refractive \\
\hline Optical diameter & $6.0 \mathrm{~mm}$ & $6.0 \mathrm{~mm}$ & $6.0 \mathrm{~mm}$ \\
\hline Diffractive zone & Central $4.5 \mathrm{~mm}$ zone (with 16 rings) & $4.5 \mathrm{~mm}$ & - \\
\hline Overall diameter & $12.50 \mathrm{~mm}$ & $13.0 \mathrm{~mm}$ & $13.0 \mathrm{~mm}$ \\
\hline Optic & $\begin{array}{l}\text { Biconvex, aberration-neutral } \\
\text { technology, with Amon-Apple } 360^{\circ} \\
\text { enhanced square edge }\end{array}$ & $\begin{array}{l}\text { Biconvex (inner } \\
\text { diffractive and outer } \\
\text { refractive) }\end{array}$ & Biconvex, Aspheric \\
\hline Haptic Style: & $\begin{array}{l}\text { Closed loop with anti-vaulting haptic } \\
(\mathrm{AVH}) \text { technology }\end{array}$ & 2 open-loop haptics & STABLEFORCE® Haptics \\
\hline $\begin{array}{l}\text { Estimated A- } \\
\text { constant (SRK/T, } \\
\text { optical biometry) }\end{array}$ & 118.6 & 118.95 & 118.7 \\
\hline Incision size & $\begin{array}{l}1.65 \mathrm{~mm} \text { nozzle for sub } 2.2 \mathrm{~mm} \\
\text { incision }\end{array}$ & $\geq 2.0 \mathrm{~mm}$ & $\geq 2.0 \mathrm{~mm}$ \\
\hline \multicolumn{4}{|c|}{$\begin{array}{l}\text { IOL = intraocular lens; } \mathrm{D}=\text { dioptres } \\
\text { The RayOne Trifocal intraocular lens is manufactured by Rayner, UK; the two AcrySof IQ intraocular lenses is } \\
\text { manufactured by Alcon Laboratories, Fort Worth, TX. }\end{array}$} \\
\hline
\end{tabular}


Table 2

Postoperative monocular uncorrected and corrected visual acuity (logMAR) results at all follow-up visits.

\begin{tabular}{|c|c|c|c|c|c|c|c|c|c|}
\hline \multicolumn{4}{|c|}{1 month } & \multicolumn{3}{|l|}{3 months } & \multicolumn{3}{|c|}{12 months } \\
\hline Parameter & RayOne & PanOptix & $\begin{array}{l}\text { IQ } \\
\text { Mono }\end{array}$ & RayOne & PanOptix & $\begin{array}{l}\text { IQ } \\
\text { Mono }\end{array}$ & RayOne & PanOptix & $\begin{array}{l}\text { IQ } \\
\text { Mono }\end{array}$ \\
\hline \multicolumn{10}{|l|}{ UDVA } \\
\hline $\begin{array}{l}\text { Mean } \pm \\
\text { SD }\end{array}$ & $\begin{array}{l}0.03 \pm \\
0.05^{\star}\end{array}$ & $\begin{array}{l}0.04 \pm \\
0.05\end{array}$ & $\begin{array}{l}0.08 \pm \\
0.07\end{array}$ & $\begin{array}{l}0.01 \pm \\
0.05^{\star}\end{array}$ & $\begin{array}{l}0.03 \pm \\
0.05\end{array}$ & $\begin{array}{l}0.05 \pm \\
0.05\end{array}$ & $\begin{array}{l}-0.01 \pm \\
0.03^{\star}\end{array}$ & $\begin{array}{l}0.01 \pm \\
0.06\end{array}$ & $\begin{array}{l}0.04 \\
\pm 0.05\end{array}$ \\
\hline Range & $\begin{array}{l}0.00 \\
0.10\end{array}$ & $\begin{array}{l}0.00 \\
0.10\end{array}$ & $\begin{array}{l}0.00 \\
0.20\end{array}$ & $\begin{array}{l}-0.10 \\
0.10\end{array}$ & $\begin{array}{l}0.00 \\
0.10\end{array}$ & $\begin{array}{l}0.00 \\
0.10\end{array}$ & $\begin{array}{l}-0.10 \\
0.10\end{array}$ & $\begin{array}{l}-0.10 \\
0.10\end{array}$ & $\begin{array}{l}0.00 \\
0.10\end{array}$ \\
\hline \multicolumn{10}{|l|}{ DCVA } \\
\hline $\begin{array}{l}\text { Mean + } \\
\text { SD }\end{array}$ & $\begin{array}{l}0.00 \pm \\
0.00\end{array}$ & $\begin{array}{l}0.00 \pm \\
0.00\end{array}$ & $\begin{array}{l}0.00 \pm \\
0.00\end{array}$ & $\begin{array}{l}-0.01 \pm \\
0.03\end{array}$ & $\begin{array}{l}0.00 \pm \\
0.00\end{array}$ & $\begin{array}{l}0.00 \pm \\
0.00\end{array}$ & $\begin{array}{l}-0.02 \pm \\
0.04\end{array}$ & $\begin{array}{l}0.00 \pm \\
0.00\end{array}$ & $\begin{array}{l}0.00 \\
\pm 0.00\end{array}$ \\
\hline Range & $\begin{array}{l}0.00 \\
0.00\end{array}$ & $\begin{array}{l}0.00 \\
0.00\end{array}$ & $\begin{array}{l}0.00 \\
0.00\end{array}$ & $\begin{array}{l}-0.10 \\
0.00\end{array}$ & $\begin{array}{l}0.00 \\
0.00\end{array}$ & $\begin{array}{l}0.00 \\
0.00\end{array}$ & $\begin{array}{l}-0.10 \\
0.10\end{array}$ & $\begin{array}{l}0.00 \\
0.00\end{array}$ & $\begin{array}{l}0.00 \\
0.00\end{array}$ \\
\hline \multicolumn{10}{|l|}{ UIVA } \\
\hline $\begin{array}{l}\text { Mean } \pm \\
\text { SD }\end{array}$ & $\begin{array}{l}0.19 \pm \\
0.05^{\star \star}\end{array}$ & $\begin{array}{l}0.19 \pm \\
0.06^{\star \star}\end{array}$ & $\begin{array}{l}0.68 \pm \\
0.08\end{array}$ & $\begin{array}{l}0.10 \pm \\
0.05^{\star \star}\end{array}$ & $\begin{array}{l}0.14 \pm \\
0.07^{\star \star}\end{array}$ & $\begin{array}{l}0.66 \pm \\
0.06\end{array}$ & $\begin{array}{l}0.06 \pm \\
0.05^{\star \star}\end{array}$ & $\begin{array}{l}0.09 \pm \\
0.05^{\star \star}\end{array}$ & $\begin{array}{l}0.56 \\
\pm 0.05\end{array}$ \\
\hline Range & $\begin{array}{l}0.10 \\
0.30\end{array}$ & $\begin{array}{l}0.10 \\
0.30\end{array}$ & $\begin{array}{l}0.60 \\
0.80\end{array}$ & $\begin{array}{l}0.10 \\
0.20\end{array}$ & $\begin{array}{l}0.10 \\
0.30\end{array}$ & $\begin{array}{l}0.60 \\
0.80\end{array}$ & $\begin{array}{l}0.00 \\
0.10\end{array}$ & $\begin{array}{l}0.00 \\
0.20\end{array}$ & $\begin{array}{l}0.50 \\
0.60\end{array}$ \\
\hline \multicolumn{10}{|l|}{ DCIVA } \\
\hline $\begin{array}{l}\text { Mean } \pm \\
\text { SD }\end{array}$ & $\begin{array}{l}0.08 \pm \\
0.05\end{array}$ & $\begin{array}{l}0.09 \pm \\
0.06\end{array}$ & $\begin{array}{l}0.10 \pm \\
0.06\end{array}$ & $\begin{array}{l}0.08 \pm \\
0.04\end{array}$ & $\begin{array}{l}0.10 \pm \\
0.06\end{array}$ & $\begin{array}{l}0.08 \pm \\
0.04\end{array}$ & $\begin{array}{l}0.03 \pm \\
0.04\end{array}$ & $\begin{array}{l}0.06 \pm \\
0.06\end{array}$ & $\begin{array}{l}0.05 \\
\pm 0.05\end{array}$ \\
\hline Range & $\begin{array}{l}0.00 \\
0.20\end{array}$ & $\begin{array}{l}0.00 \\
0.20\end{array}$ & $\begin{array}{l}0.00 \\
0.20\end{array}$ & $\begin{array}{l}0.00 \\
0.10\end{array}$ & $\begin{array}{l}0.00 \\
0.20\end{array}$ & $\begin{array}{l}0.00 \\
0.10\end{array}$ & $\begin{array}{l}0.00 \\
0.10\end{array}$ & $\begin{array}{l}0.00 \\
0.20\end{array}$ & $\begin{array}{l}0.00 \\
0.10\end{array}$ \\
\hline \multicolumn{10}{|l|}{ UNVA } \\
\hline $\begin{array}{l}\text { Mean } \pm \\
\text { SD }\end{array}$ & $\begin{array}{l}0.09 \pm \\
0.09 * \star\end{array}$ & $\begin{array}{l}0.11 \pm \\
0.08^{\star \star}\end{array}$ & $\begin{array}{l}0.69 \pm \\
0.09\end{array}$ & $\begin{array}{l}0.04 \pm \\
0.05^{\star \star}\end{array}$ & $\begin{array}{l}0.07 \pm \\
0.05^{\star \star}\end{array}$ & $\begin{array}{l}0.65 \pm \\
0.07\end{array}$ & $\begin{array}{l}0.03 \pm \\
0.04^{\star \star}\end{array}$ & $\begin{array}{l}0.04 \pm \\
0.05^{\star \star}\end{array}$ & $\begin{array}{l}0.58 \\
\pm 0.09\end{array}$ \\
\hline Range & $\begin{array}{l}0.00 \\
0.20\end{array}$ & $\begin{array}{l}0.00 \\
0.20\end{array}$ & $\begin{array}{l}0.50 \\
0.80\end{array}$ & $\begin{array}{l}0.00 \\
0.10\end{array}$ & $\begin{array}{l}0.00 \\
0.10\end{array}$ & $\begin{array}{l}0.50 \\
0.80\end{array}$ & $\begin{array}{l}0.00 \\
0.10\end{array}$ & $\begin{array}{l}0.00 \\
0.10\end{array}$ & $\begin{array}{l}0.40 \\
0.70\end{array}$ \\
\hline \multicolumn{10}{|l|}{ DCNVA } \\
\hline $\begin{array}{l}\text { Mean + } \\
\text { SD }\end{array}$ & $\begin{array}{l}0.00 \pm \\
0.00\end{array}$ & $\begin{array}{l}0.00 \pm \\
0.00\end{array}$ & $\begin{array}{l}0.00 \pm \\
0.00\end{array}$ & $\begin{array}{l}0.00 \pm \\
0.00\end{array}$ & $\begin{array}{l}0.01 \pm \\
0.03\end{array}$ & $\begin{array}{l}0.00 \pm \\
0.00\end{array}$ & $\begin{array}{l}0.00 \pm \\
0.00\end{array}$ & $\begin{array}{l}0.00 \pm \\
0.00\end{array}$ & $\begin{array}{l}0.00 \\
\pm 0.00\end{array}$ \\
\hline Range & $\begin{array}{l}0.00 \\
0.00\end{array}$ & $\begin{array}{l}0.00 \\
0.00\end{array}$ & $\begin{array}{l}0.00 \\
0.00\end{array}$ & $\begin{array}{l}0.00 \\
0.00\end{array}$ & $\begin{array}{l}0.00 \\
0.10\end{array}$ & $\begin{array}{l}0.00 \\
0.00\end{array}$ & $\begin{array}{l}0.00 \\
0.00\end{array}$ & $\begin{array}{l}0.00 \\
0.00\end{array}$ & $\begin{array}{l}0.00 \\
0.00\end{array}$ \\
\hline $\begin{array}{l}\text { *: } P<0.01 \\
\text { UDVA: unc } \\
\text { visual acui } \\
\text { distance-c }\end{array}$ & $\begin{array}{l}\text { AcrySof } \\
\text { cted dis } \\
\text { DCIVA: d } \\
\text { cted nea }\end{array}$ & $\begin{array}{l}\text { Mono; **: } \\
\text { ee visual } \\
\text { nce-corre } \\
\text { sual acuit }\end{array}$ & $\begin{array}{l}0.001 \\
\text { ty; CD } \\
\text { intern }\end{array}$ & $\begin{array}{l}\text { crySof I } \\
\text { distance } \\
\text { ate visu }\end{array}$ & $\begin{array}{l}\text { lono } \\
\text { rected vis } \\
\text { cuity; UN }\end{array}$ & $\begin{array}{l}\text { acuity } \\
\text { uncorre }\end{array}$ & $\begin{array}{l}\text { JA: unco } \\
\text { d near v }\end{array}$ & $\begin{array}{l}\text { cted interm } \\
\text { al acuity; }\end{array}$ & $\begin{array}{l}\text { diate } \\
\text { NVA: }\end{array}$ \\
\hline
\end{tabular}


Table 3

Postoperative binocular uncorrected and corrected visual acuity (logMAR) results at all follow-up visits.

\begin{tabular}{|c|c|c|c|c|c|c|c|c|c|}
\hline \multicolumn{4}{|c|}{1 month } & \multicolumn{3}{|c|}{3 months } & \multicolumn{3}{|c|}{12 months } \\
\hline Parameter & RayOne & PanOptix & $\begin{array}{l}\text { IQ } \\
\text { Mono }\end{array}$ & RayOne & PanOptix & $\begin{array}{l}\text { IQ } \\
\text { Mono }\end{array}$ & RayOne & PanOptix & $\begin{array}{l}\text { IQ } \\
\text { Mono }\end{array}$ \\
\hline \multicolumn{10}{|l|}{ UDVA } \\
\hline $\begin{array}{l}\text { Mean } \pm \\
\text { SD }\end{array}$ & $\begin{array}{l}0.01 \pm \\
0.04^{\star}\end{array}$ & $\begin{array}{l}0.03 \pm \\
0.05\end{array}$ & $\begin{array}{l}0.05 \pm \\
0.05\end{array}$ & $\begin{array}{l}-0.03 \pm \\
0.05^{\star}\end{array}$ & $\begin{array}{l}-0.01 \pm \\
0.04\end{array}$ & $\begin{array}{l}0.03 \pm \\
0.05\end{array}$ & $\begin{array}{l}-0.04 \pm \\
0.05^{\star}\end{array}$ & $\begin{array}{l}-0.03 \pm \\
0.05\end{array}$ & $\begin{array}{l}0.01 \pm \\
0.06\end{array}$ \\
\hline Range & $\begin{array}{l}0.00 \\
0.00\end{array}$ & $\begin{array}{l}0.00 \\
0.10\end{array}$ & $\begin{array}{l}0.00 \\
0.10\end{array}$ & $\begin{array}{l}-0.10 \\
0.00\end{array}$ & $\begin{array}{l}-0.10 \\
0.00\end{array}$ & $\begin{array}{l}-0.01 \\
0.10\end{array}$ & $\begin{array}{l}-0.10 \\
0.10\end{array}$ & $\begin{array}{l}-0.10 \\
0.00\end{array}$ & $\begin{array}{l}-0.10 \\
0.10\end{array}$ \\
\hline \multicolumn{10}{|l|}{ DCVA } \\
\hline $\begin{array}{l}\text { Mean + } \\
\text { SD }\end{array}$ & $\begin{array}{l}0.00 \pm \\
0.00\end{array}$ & $\begin{array}{l}0.00 \pm \\
0.00\end{array}$ & $\begin{array}{l}0.00 \pm \\
0.00\end{array}$ & $\begin{array}{l}-0.04 \pm \\
0.05\end{array}$ & $\begin{array}{l}-0.01 \pm \\
0.04\end{array}$ & $\begin{array}{l}0.00 \pm \\
0.00\end{array}$ & $\begin{array}{l}-0.05 \pm \\
0.05\end{array}$ & $\begin{array}{l}-0.01 \pm \\
0.04\end{array}$ & $\begin{array}{l}-0.03 \\
\pm 0.05\end{array}$ \\
\hline Range & $\begin{array}{l}0.00 \\
0.00\end{array}$ & $\begin{array}{l}0.00 \\
0.00\end{array}$ & $\begin{array}{l}0.00 \\
0.00\end{array}$ & $\begin{array}{l}-0.10 \\
0.00\end{array}$ & $\begin{array}{l}-0.10 \\
0.00\end{array}$ & $\begin{array}{l}0.00 \\
0.00\end{array}$ & $\begin{array}{l}-0.10 \\
0.00\end{array}$ & $\begin{array}{l}-0.10 \\
0.00\end{array}$ & $\begin{array}{l}-0.10 \\
0.00\end{array}$ \\
\hline \multicolumn{10}{|l|}{ UIVA } \\
\hline $\begin{array}{l}\text { Mean } \pm \\
\text { SD }\end{array}$ & $\begin{array}{l}0.09 \pm \\
0.03^{\star \star}\end{array}$ & $\begin{array}{l}0.1 \pm \\
0.07 \star \star\end{array}$ & $\begin{array}{l}0.63 \pm \\
0.05\end{array}$ & $\begin{array}{l}0.04 \pm \\
0.07 * \star\end{array}$ & $\begin{array}{l}0.03 \pm \\
0.07^{\star \star}\end{array}$ & $\begin{array}{l}0.61 \pm \\
0.03\end{array}$ & $\begin{array}{l}0.02 \pm \\
0.06^{\star \star}\end{array}$ & $\begin{array}{l}0.02 \pm \\
0.06^{\star \star}\end{array}$ & $\begin{array}{l}0.56 \pm \\
0.04\end{array}$ \\
\hline Range & $\begin{array}{l}0.00 \\
0.10\end{array}$ & $\begin{array}{l}0.00 \\
0.20\end{array}$ & $\begin{array}{l}0.60 \\
0.70\end{array}$ & $\begin{array}{l}-0.10 \\
0.10\end{array}$ & $\begin{array}{l}-0.10 \\
0.10\end{array}$ & $\begin{array}{l}0.60 \\
0.70\end{array}$ & $\begin{array}{l}-0.10 \\
0.10\end{array}$ & $\begin{array}{l}-0.10 \\
0.10\end{array}$ & $\begin{array}{l}0.50 \\
0.60\end{array}$ \\
\hline \multicolumn{10}{|l|}{ DCIVA } \\
\hline $\begin{array}{l}\text { Mean } \pm \\
\text { SD }\end{array}$ & $\begin{array}{l}0.00 \pm \\
0.00\end{array}$ & $\begin{array}{l}0.03 \pm \\
0.05\end{array}$ & $\begin{array}{l}0.05 \pm \\
0.05\end{array}$ & $\begin{array}{l}-0.01 \pm \\
0.04\end{array}$ & $\begin{array}{l}0.01 \pm \\
0.06\end{array}$ & $\begin{array}{l}0.03 \pm \\
0.05\end{array}$ & $\begin{array}{l}0.00 \pm \\
0.05\end{array}$ & $\begin{array}{l}0.01 \pm \\
0.06\end{array}$ & $\begin{array}{l}0.01 \pm \\
0.04\end{array}$ \\
\hline Range & $\begin{array}{l}0.00 \\
0.00\end{array}$ & $\begin{array}{l}0.00 \\
0.10\end{array}$ & $\begin{array}{l}0.00 \\
0.10\end{array}$ & $\begin{array}{l}-0.10 \\
0.00\end{array}$ & $\begin{array}{l}-0.10 \\
0.10\end{array}$ & $\begin{array}{l}0.00 \\
0.10\end{array}$ & $\begin{array}{l}-0.10 \\
0.10\end{array}$ & $\begin{array}{l}-0.10 \\
0.10\end{array}$ & $\begin{array}{l}0.00 \\
0.10\end{array}$ \\
\hline \multicolumn{10}{|l|}{ UNVA } \\
\hline $\begin{array}{l}\text { Mean } \pm \\
\text { SD }\end{array}$ & $\begin{array}{l}0.06 \pm \\
0.05^{\star \star}\end{array}$ & $\begin{array}{l}0.06 \pm \\
0.05^{\star \star}\end{array}$ & $\begin{array}{l}0.65 \pm \\
0.05\end{array}$ & $\begin{array}{l}-0.01 \pm \\
0.04^{\star \star}\end{array}$ & $\begin{array}{l}0.01 \pm \\
0.06 * *\end{array}$ & $\begin{array}{l}0.61 \pm \\
0.06\end{array}$ & $\begin{array}{l}-0.03 \pm \\
0.05^{\star *}\end{array}$ & $\begin{array}{l}-0.01 \pm \\
0.04^{\star \star}\end{array}$ & $\begin{array}{l}0.54 \pm \\
0.07\end{array}$ \\
\hline Range & $\begin{array}{l}0.00 \\
0.10\end{array}$ & $\begin{array}{l}0.00 \\
0.10\end{array}$ & $\begin{array}{l}0.60 \\
0.70\end{array}$ & $\begin{array}{l}-0.10 \\
0.00\end{array}$ & $\begin{array}{l}-0.10 \\
0.10\end{array}$ & $\begin{array}{l}-0.10 \\
0.00\end{array}$ & $\begin{array}{l}-0.10 \\
0.00\end{array}$ & $\begin{array}{l}-0.00 \\
0.00\end{array}$ & $\begin{array}{l}0.40 \\
0.60\end{array}$ \\
\hline \multicolumn{10}{|l|}{ DCNVA } \\
\hline $\begin{array}{l}\text { Mean + } \\
\text { SD }\end{array}$ & $\begin{array}{l}0.00 \pm \\
0.00\end{array}$ & $\begin{array}{l}0.00 \pm \\
0.00\end{array}$ & $\begin{array}{l}0.00 \pm \\
0.00\end{array}$ & $\begin{array}{l}-0.03 \pm \\
0.05\end{array}$ & $\begin{array}{l}-0.01 \pm \\
0.04\end{array}$ & $\begin{array}{l}-0.01 \\
\pm 0.04\end{array}$ & $\begin{array}{l}-0.05 \pm \\
0.05\end{array}$ & $\begin{array}{l}-0.01 \pm \\
0.04\end{array}$ & $\begin{array}{l}-0.03 \\
\pm 0.05\end{array}$ \\
\hline Range & $\begin{array}{l}0.00 \\
0.00\end{array}$ & $\begin{array}{l}0.00 \\
0.00\end{array}$ & $\begin{array}{l}0.00 \\
0.00\end{array}$ & $\begin{array}{l}-0.10 \\
0.00\end{array}$ & $\begin{array}{l}-0.10 \\
0.00\end{array}$ & $\begin{array}{l}-0.10 \\
0.00\end{array}$ & $\begin{array}{l}-0.10 \\
0.00\end{array}$ & $\begin{array}{l}-0.10 \\
0.00\end{array}$ & $\begin{array}{l}-0.10 \\
0.00\end{array}$ \\
\hline $\begin{array}{l}\text { *: } P<0.01 \\
\text { UDVA: unc } \\
\text { visual acui } \\
\text { distance-c }\end{array}$ & $\begin{array}{l}\text { AcrySof } \\
\text { cted dis } \\
\text { DCIVA: d } \\
\text { cted nea }\end{array}$ & $\begin{array}{l}\text { Mono; } \\
\text { ze visual } \\
\text { nce-correc } \\
\text { sual acuit }\end{array}$ & $\begin{array}{l}0.001 \\
\text { ity; CD } \\
\text { d inter }\end{array}$ & $\begin{array}{l}\text { AcrySof } \\
\text { distanc } \\
\text { liate visu }\end{array}$ & $\begin{array}{l}\text { Mono } \\
\text { rrected } \\
\text { acuity; U }\end{array}$ & $\begin{array}{l}\text { I acuit } \\
\text { uncor }\end{array}$ & $\begin{array}{l}\text { A: unc } \\
\text { d near }\end{array}$ & ted interm & $\begin{array}{l}\text { diate } \\
\text { iNVA: }\end{array}$ \\
\hline
\end{tabular}


Table 4

Mean Aberrometry Outcomes at 12 months after surgery.

\begin{tabular}{|c|c|c|c|c|c|c|c|c|c|c|}
\hline & & \multicolumn{3}{|l|}{ RayOne } & \multicolumn{3}{|c|}{ PanOptix } & \multicolumn{3}{|c|}{ AcrySof Monofocal } \\
\hline & & $\begin{array}{l}\text { Mean } \\
\text { RMS } \\
\text { Value } \\
(\mu \mathrm{m})\end{array}$ & $\begin{array}{l}\text { St } \\
\text { Dev }\end{array}$ & Median & $\begin{array}{l}\text { Mean } \\
\text { RMS } \\
\text { Value } \\
(\mu \mathrm{m})\end{array}$ & $\begin{array}{l}\text { St } \\
\text { Dev }\end{array}$ & Median & $\begin{array}{l}\text { Mean } \\
\text { RMS } \\
\text { Value } \\
(\mu \mathrm{m})\end{array}$ & $\begin{array}{l}\text { St } \\
\text { Dev }\end{array}$ & Median \\
\hline \multirow[t]{3}{*}{ Ocular } & Total & 0.538 & 0.254 & 0.460 & 0.543 & 0.184 & 0.580 & 0.453 & 0.198 & 0.450 \\
\hline & LOA & 0.462 & 0.239 & 0.405 & 0.491 & 0.175 & 0.525 & 0.408 & 0.181 & 0.415 \\
\hline & HOA & 0.141 & 0.043 & 0.140 & 0.187 & 0.103 & 0.170 & 0.157 & 0.068 & 0.150 \\
\hline \multirow[t]{3}{*}{ Corneal } & Total & 0.226 & 0.111 & 0.185 & 0.246 & 0.061 & 0.230 & 0.243 & 0.066 & 0.220 \\
\hline & LOA & 0.162 & 0.112 & 0.120 & 0.188 & 0.059 & 0.185 & 0.181 & 0.098 & 0.190 \\
\hline & HOA & 0.145 & 0.057 & 0.125 & 0.146 & 0.058 & 0.130 & 0.154 & 0.062 & 0.155 \\
\hline \multirow[t]{9}{*}{ Internal } & Total & 0.490 & 0.270 & 0.470 & 0.539 & 0.242 & 0.565 & 0.426 & 0.205 & 0.435 \\
\hline & LOA & 0.438 & 0.272 & 0.395 & 0.471 & 0.183 & 0.495 & 0.348 & 0.170 & 0.405 \\
\hline & HOA & 0.145 & 0.049 & 0.120 & 0.176 & 0.076 & 0.170 & 0.147 & 0.060 & 0.165 \\
\hline & $\begin{array}{l}\text { LOA: } \\
\text { Defocus }\end{array}$ & -0.451 & 0.295 & -0.355 & -0.422 & 0.216 & -0.435 & -0.287 & 0.269 & -0.275 \\
\hline & $\begin{array}{l}\text { LOA: } \\
\text { Astigmatism }\end{array}$ & 0.196 & 0.090 & 0.190 & 0.165 & 0.110 & 0.170 & 0.147 & 0.045 & 0.155 \\
\hline & $\begin{array}{l}\text { HOA: } \\
\text { Primary } \\
\text { Coma }\end{array}$ & 0.058 & 0.033 & 0.050 & 0.071 & 0.059 & 0.055 & 0.085 & 0.049 & 0.080 \\
\hline & HOA: Trefoil & 0.071 & 0.038 & 0.060 & 0.094 & 0.061 & 0.090 & 0.128 & 0.107 & 0.095 \\
\hline & $\begin{array}{l}\text { HOA: } \\
\text { Primary } \\
\text { Spherical } \\
\text { Aberration }\end{array}$ & -0.004 & 0.049 & 0.005 & 0.013 & 0.032 & 0.010 & 0.014 & 0.036 & 0.025 \\
\hline & $\begin{array}{l}\text { Pupil } \\
\text { Diameter } \\
(\mathrm{mm})\end{array}$ & 3.486 & 0.499 & 3.440 & 3.739 & 0.598 & 3.930 & 3.808 & 0.878 & 3.885 \\
\hline
\end{tabular}

\section{Figures}



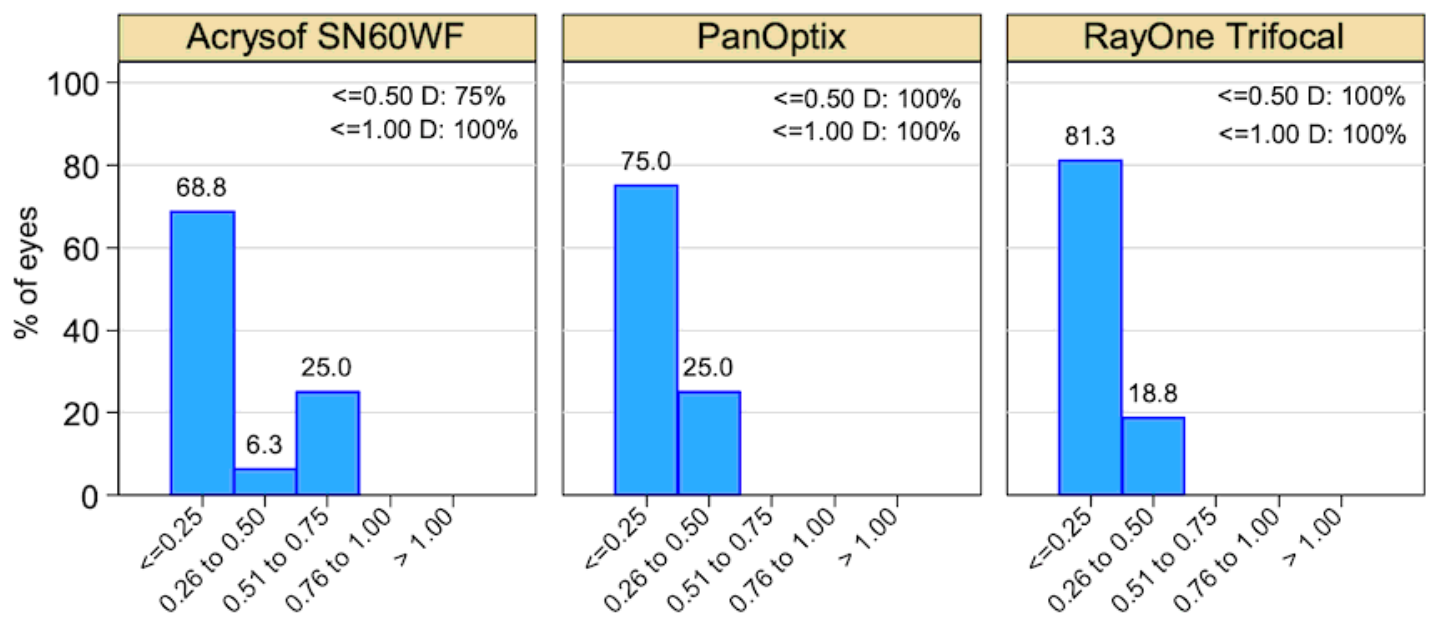

Postoperative Refractive Cylinder (D)

B

Spherical Equivalent Refraction Accuracy
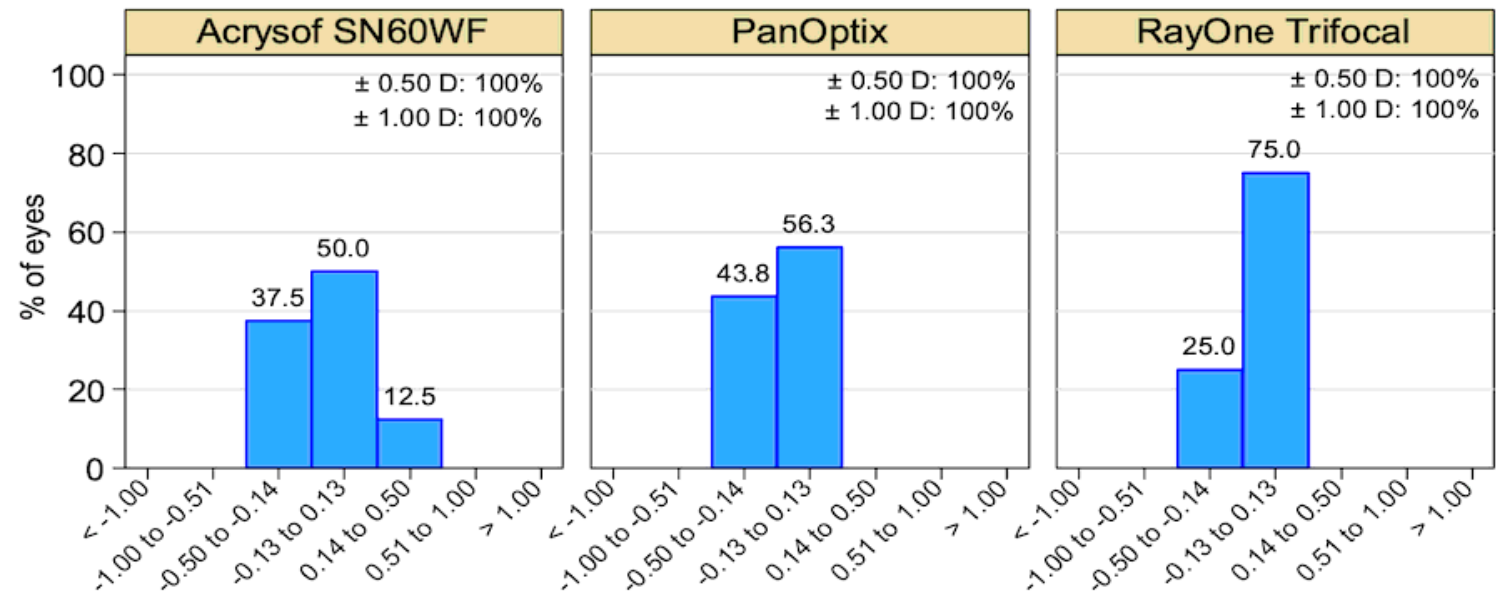

Accuracy of SEQ (D)

Figure 1

Distribution of the (A) postoperative refractive cylinder and (B) manifest spherical equivalent refraction (MRSE) accuracy as measured at the 12-month follow-up visit. 

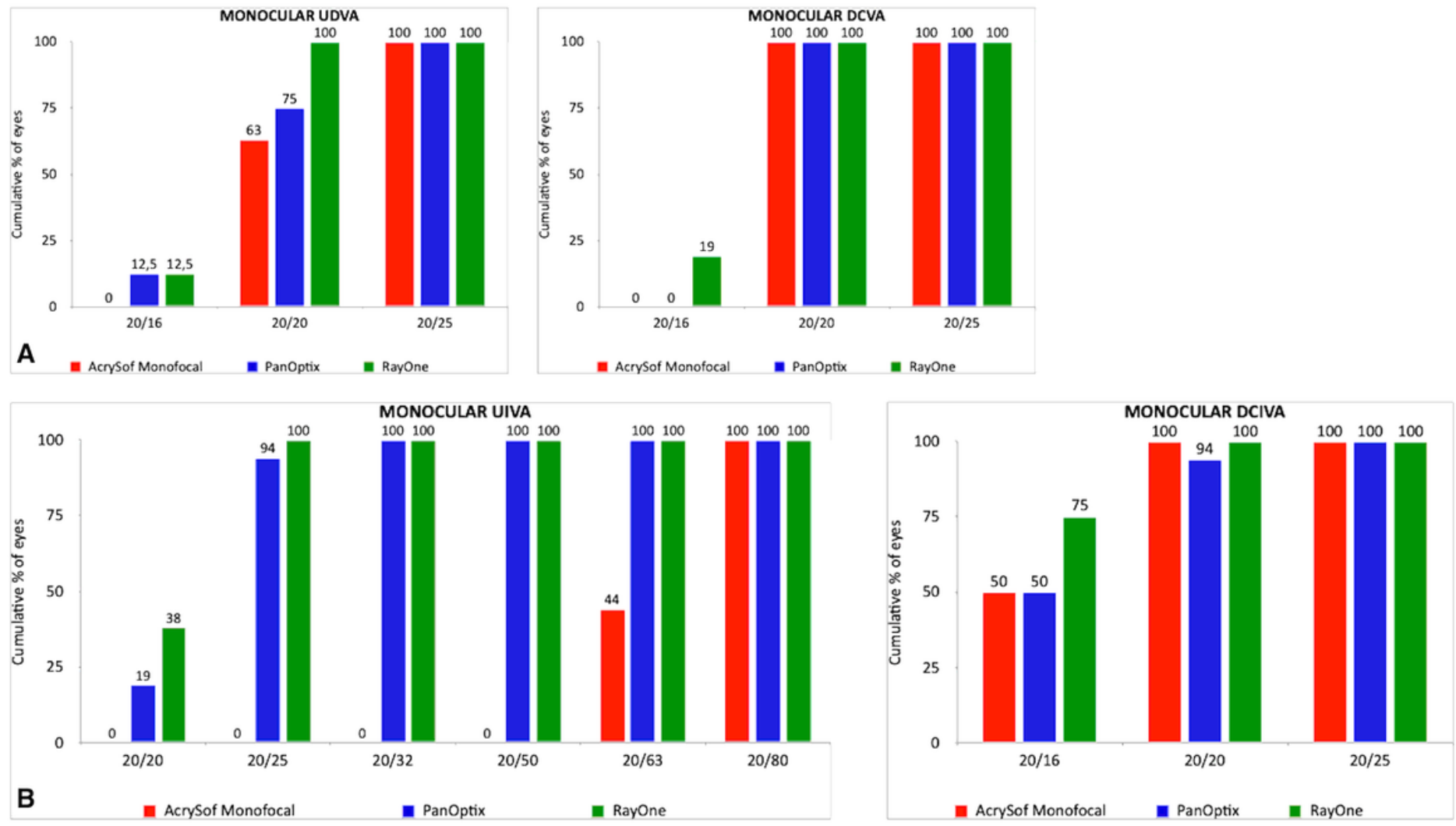

B EcrySof Monofocal - PanOptix - RayOne
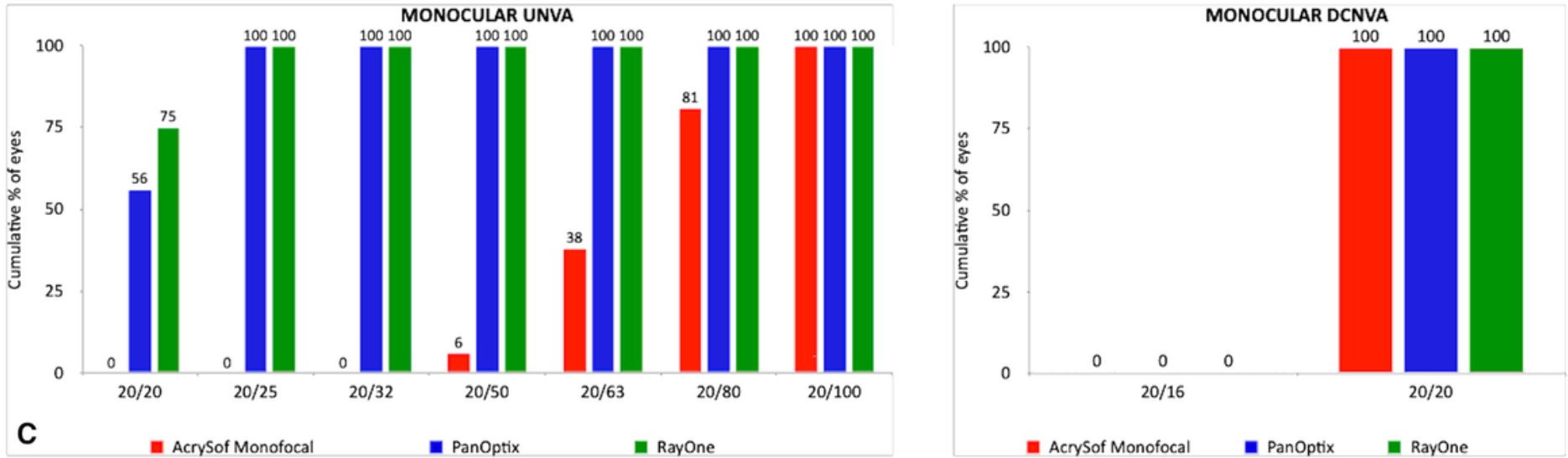

Figure 2

Cumulative distribution of post-operative monocular UDVA and DCVA (A), UIVA and DCIVA (B), and UNVA and DCNVA (B) as measured at the 12-month follow-up visit. 
A

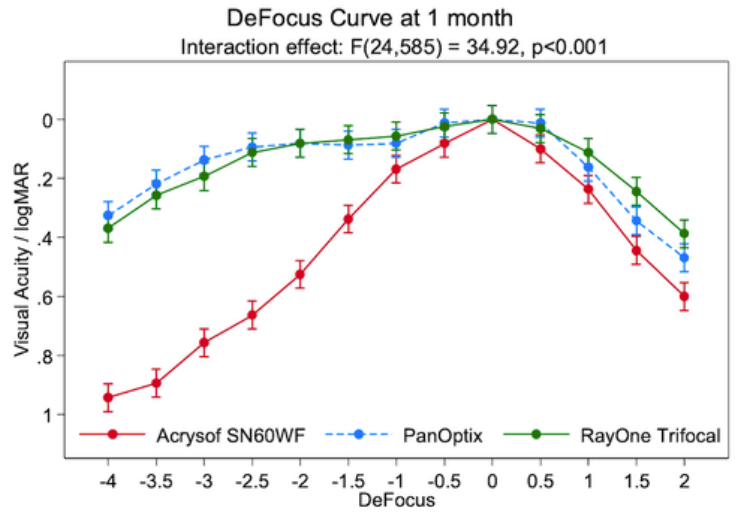

B

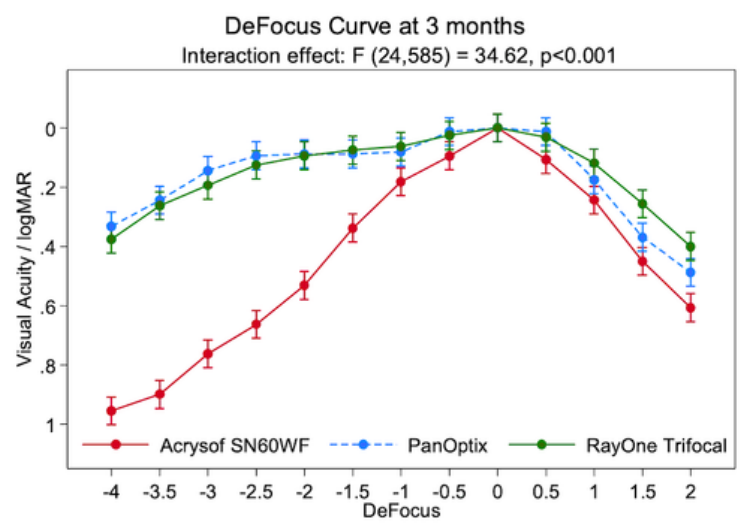

C

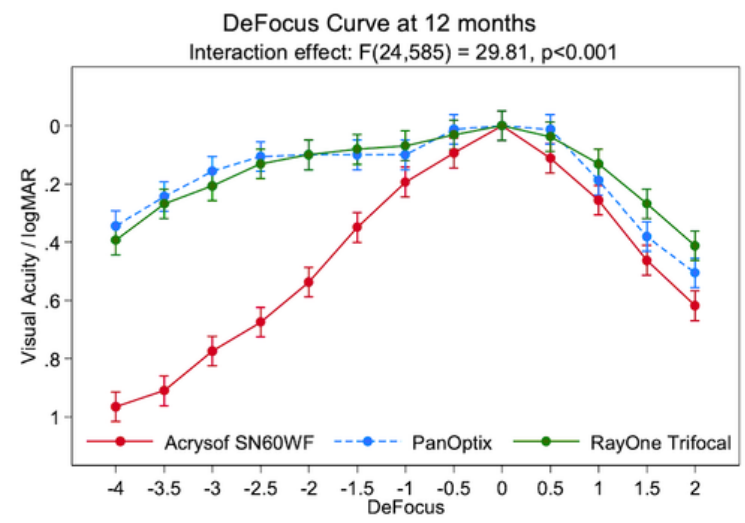

\section{Figure 3}

Binocular defocus curves under photopic conditions as calculated at (A) 1 month, (B) 3 months, (C), 12 months after cataract surgery. 
A

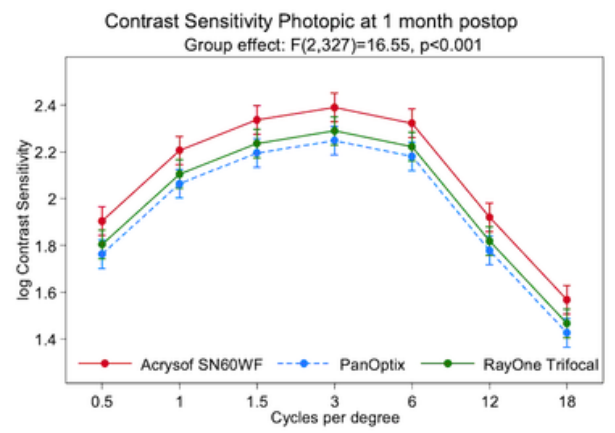

D

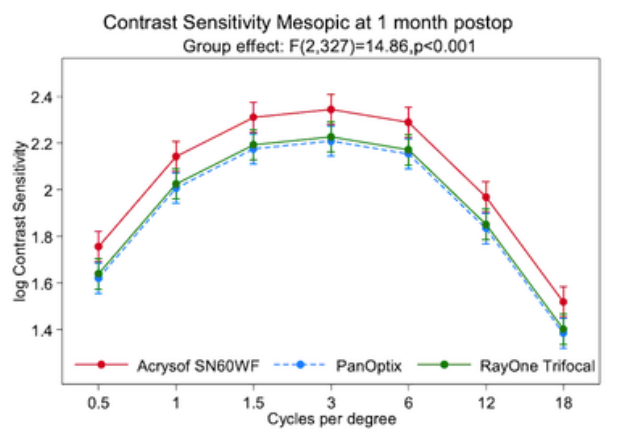

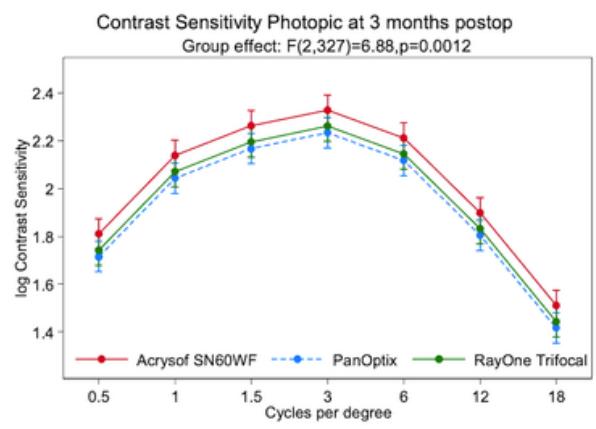

E

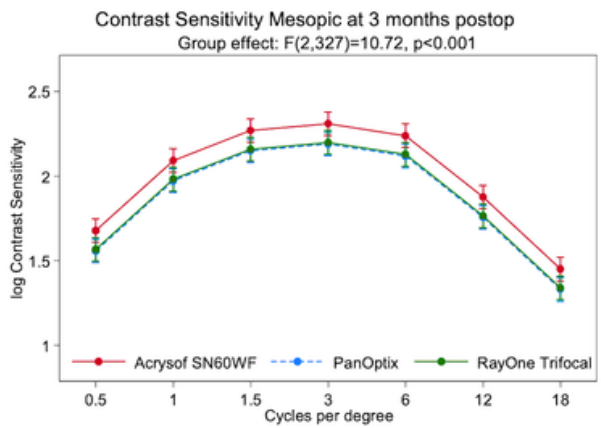

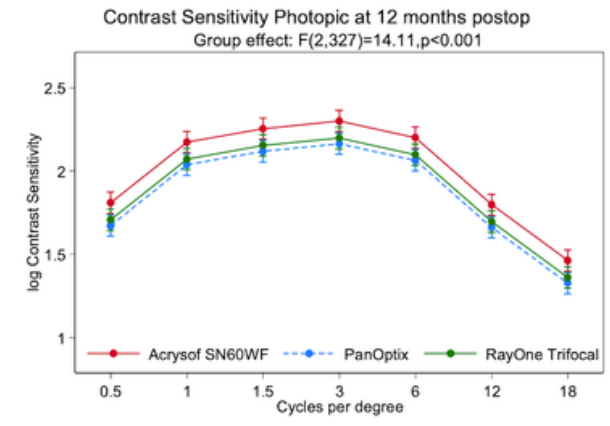

$\mathbf{F}$

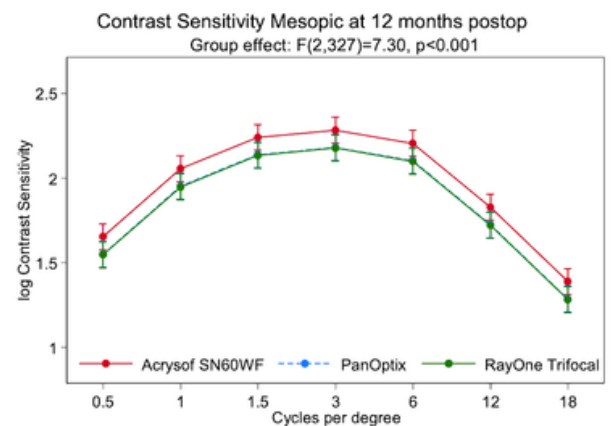

Figure 4

Results of contrast sensitivity under photopic conditions at (A) 1 month, (B) 3 months, (C), 12 months after cataract surgery, and under mesopic condition at (A) 1 month, (B) 3 months, (C), 12 months after cataract surgery.

\section{OCULAR, CORNEAL AND INTERNAL ABERRATIONS}

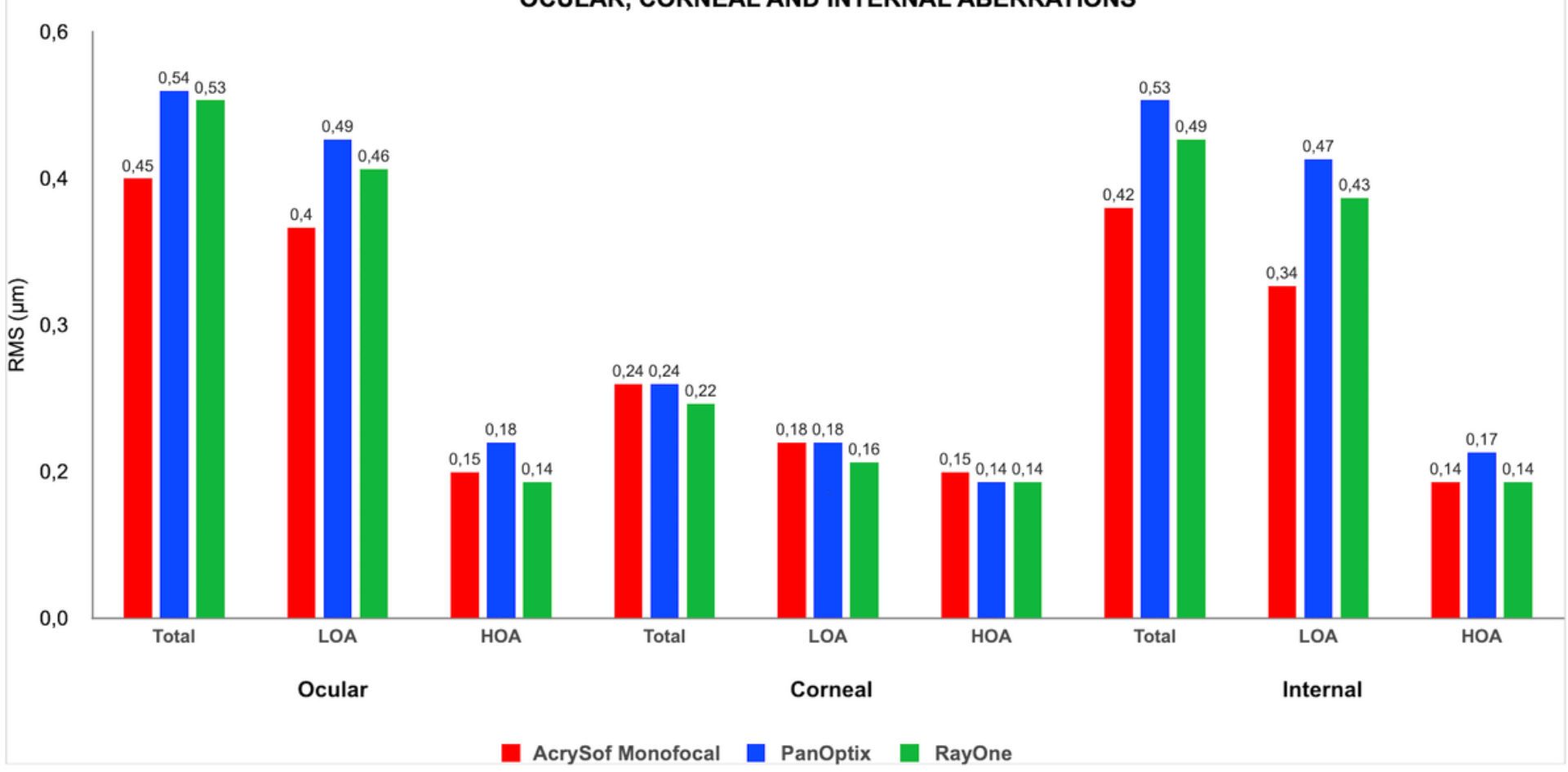

Figure 5 
Ocular, corneal and internal aberrations at the 12-month follow-up visit. Low order (LOA) and High Order (HOA) aberrations are reported for each IOL.

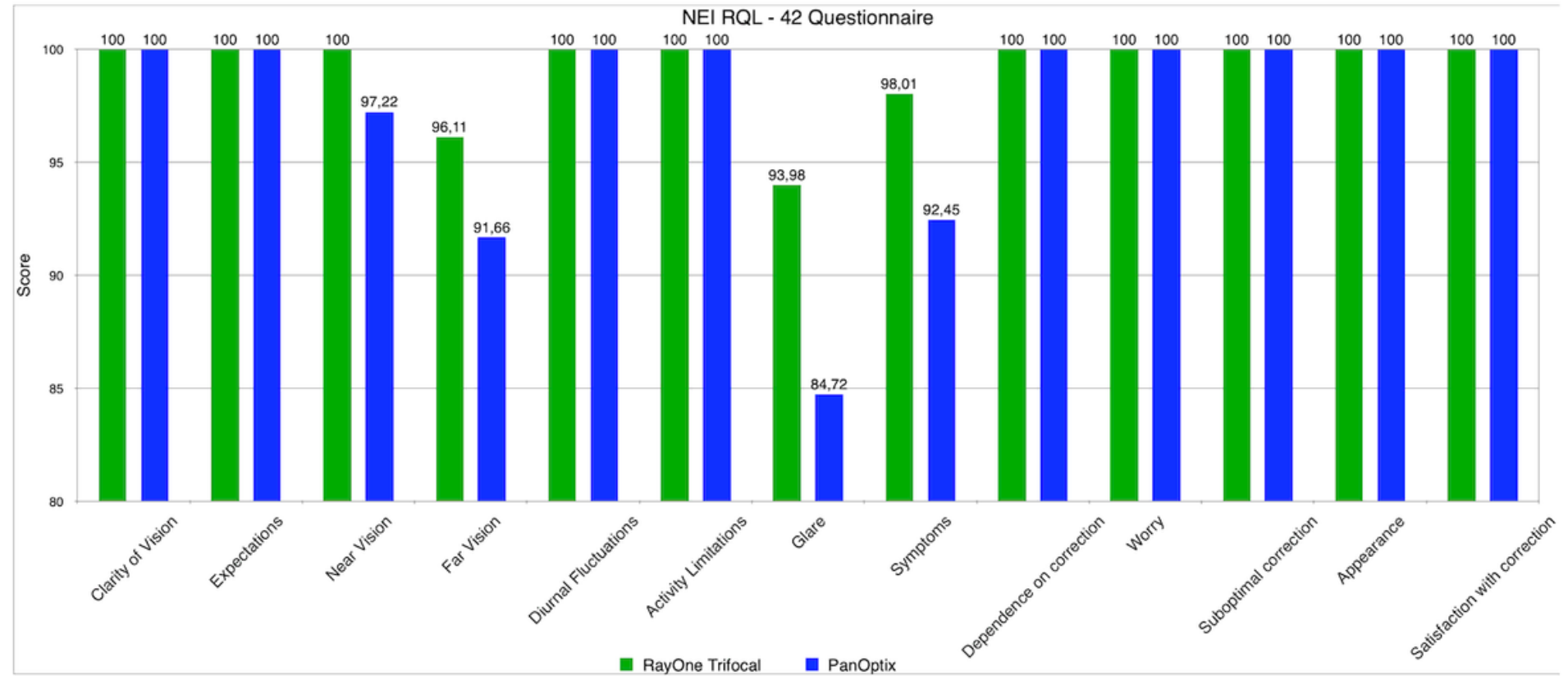

Figure 6

Results of the NEI RQL - 42 questionnaire on the visual QoL outcomes obtained at 12 months after cataract surgery. INTERNAL ABERRATIONS

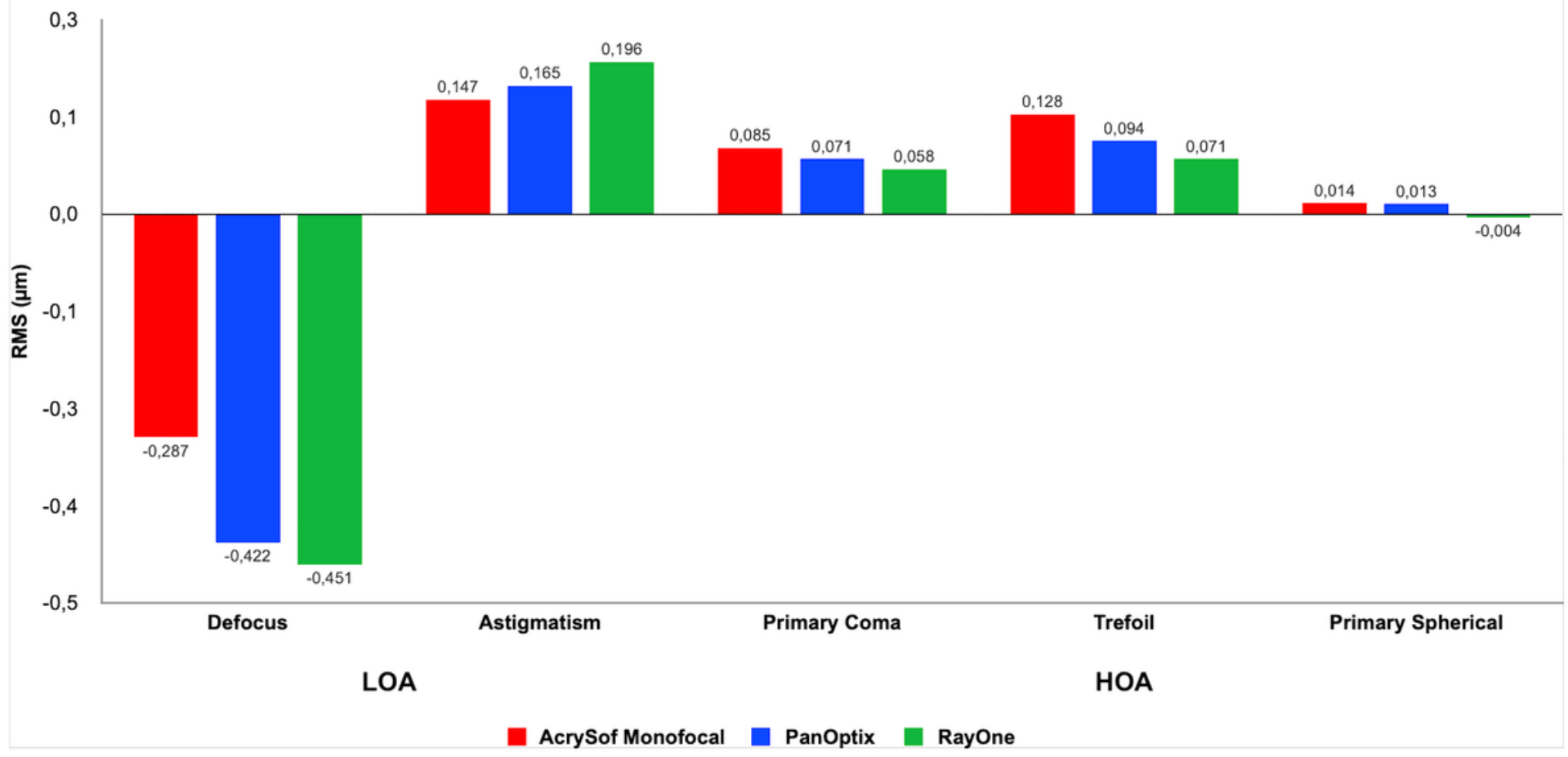

Figure 7

Internal LOA and HOA aberrations at the 12-month follow-up visit. 

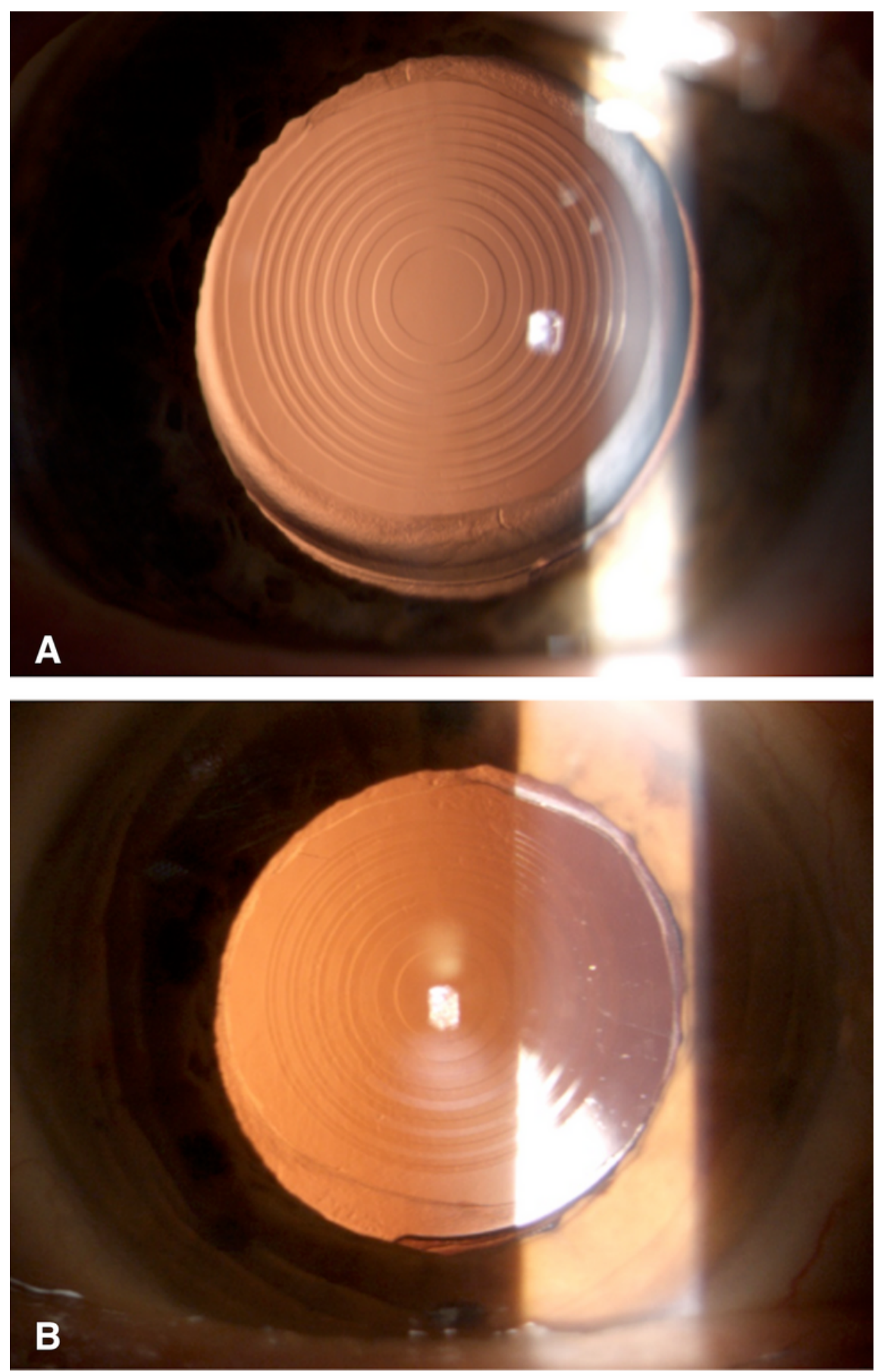

\section{Figure 8}

Digital photos of the anterior segment at the 12 month follow-up visit, showing stable centration and no opacification of the IOLs. The different diffractive profile can be appreciated. A) RayOne Trifocal, B) AcrySof IQ PanOptix. 